\title{
LEITURA RECOMBINATIVA DE PSEUDOPALAVRAS IMPRESSAS EM PSEUDOALFABETO: SIMILARIDADE ENTRE PALAVRAS E EXTENSÃO DA UNIDADE ENSINADA ${ }^{1}$
}

Elenice S. Hanna

Camila Akemi Karino Victor Tadeu Araújo Deisy das Graças de Souza²

Resumo: Controle discriminativo por elementos textuais é requisito para a leitura de palavras novas (leitura recombinativa). Este estudo empregou pseudopalavras ditadas e impressas em pseudo-alfabeto para avaliar os efeitos da similaridade entre palavras e da extensão da unidade textual ensinada sobre o desenvolvimento de leitura recombinativa. No

1 O artigo é dedicado à memória de Maria Amélia Matos, nossa mestra, parceira no interesse e na dedicação ao estudo de processos básicos de controle de estímulos subjacentes ao desenvolvimento de comportamento simbólico, e inspiradora, por seu zelo pelo rigor científico, do desenvolvimento do mini-sistema lingüístico arbitrário como um rigoroso instrumento de controle experimental.

2 A primeira e a quarta autoras são bolsistas de produtividade em pesquisa do Conselho Nacional de Desenvolvimento Científico e Tecnológico (CNPq). Camila Karino e Victor Araújo receberam bolsa de iniciação científica (PIBIC-UnB) para a realização do estudo. O estudo foi apoiado pela Fundação de Amparo à Pesquisa do Estado de São Paulo (FAPESP,Processo No.03/09928-4, para D.G.S.) e CNPq (Processo No. 400359/2008-1, para E.S.H.). Os autores estão afiliados ao Instituto Nacional de Ciência e Tecnologia sobre Comportamento, Cognição e Ensino, apoiado pela FAPESP (Processo No. 08/57705-8) e pelo CNPq (Processo No. 573972/2008-7), que apoiou a preparação do manuscrito. Agradecemos Marizete Gouveia, Maria Stella Gil e Flávio Bettarello pela ajuda com os resumos em francês e espanhol. 
Experimento 1 universitários aprenderam relações condicionais entre pseudopalavras ditadas e impressas que diferiam das incorretas em $25 \%$ ou $75 \%$ dos elementos. No Experimento 2 outros universitários aprenderam a relacionar letras ou sílabas ditadas às correspondentes modalidades impressas e subsequentemente aprenderam relações envolvendo pseudopalavras. A aquisição das discriminações foi mais rápida na Condição Diferença 75\%; a leitura recombinativa dependeu da quantidade de palavras ensinadas (Exp.1). A leitura foi mais precisa após a aprendizagem de sílabas, mas ocorreu mais recombinação após a aprendizagem de letras (Exp. 2). Combinar o ensino de palavras dissimilares e de unidades menores que a palavra pode acelerar a leitura recombinativa.

Palavras-chave: Leitura. Pseudo-alfabeto. Similaridade entre estímulos. Extensão da unidade textual. Universitários.

A leitura é uma das habilidades em que os alunos mais encontram dificuldades durante o processo de aprendizagem no ensino regular. Esta dificuldade pode ser observada nos altos índices de fracasso escolar nas séries iniciais, não apenas no Brasil. Nos Estados Unidos, um em cada seis alunos de séries iniciais apresenta dificuldade em leitura (Mueller, Olmi, \& Saunders, 2000). Entre os alunos que chegam à $4^{\text {a }}$ série do ensino fundamental no Brasil, 59\% deles não desenvolveram competência e habilidade elementares de leitura (Instituto Nacional de Estudos e Pesquisas Educacionais Anísio Teixeira [INEP], 2001).

Uma das principais razões para a dificuldade na aprendizagem de leitura e escrita reside na natureza simbólica desses comportamentos e na complexidade da rede de relações comportamentais que deve ser estabelecida até que um indivíduo se torne um leitor proficiente (e.g., de Rose, de Souza, \& Hanna, 1996; de Souza, de Rose, \& Domeniconi, 2009a; Mackay \& Sidman, 1984; Matos, Hübner, \& Peres, 1997, 1999; Matos, Avanzi \& Mcllvane, 2006; Sidman \& Cresson, 1973; Stromer, Mackay, \& Stoddard, 1992). A natureza simbólica do comportamento é definida pela arbitrariedade das relações que devem ser estabelecidas entre palavras faladas e objetos, eventos ou propriedades do mundo físico e social e entre palavras faladas e os grafemas que representam os sons.

Em uma abordagem funcional do comportamento verbal, Sidman (1971) descreveu diferentes relações entre estímulos e entre estímulos e respostas na análise da leitura: nomeação (leitura oral, ou comportamento textual), leitura com compreensão e leitura receptivo-auditiva. A leitura oral (ou comportamento textual) consiste em uma resposta vocal sob controle da palavra impressa, não implicando necessariamente em compreensão. A leitura com compreensão pode ser identificada pelo emparelhamento de figuras ou objetos às palavras impressas correspondentes e vice-versa (relação estímulo-estímulo), quando essas relações não foram diretamente ensinadas, mas derivam de relações aprendidas entre palavras ditadas, ob- 
jetos ou figuras e palavras impressas. A leitura receptivo-auditiva corresponde à seleção de uma palavra impressa (entre outras simultaneamente disponíveis) quando o estímulo modelo, em uma tarefa de emparelhamento, é uma palavra ditada. Cada tipo de comportamento pode ser adquirido independentemente dos demais (independência funcional; Skinner, 1957). No entanto, dependendo das contingências de ensino planejadas, as diferentes relações podem compartilhar estímulos que se tornam relacionados pelas contingências e passam gradualmente a formar uma rede de relações interligadas. Essa concepção ampla sobre leitura tem auxiliado:(1) na pesquisa sobre os processos básicos de aprendizagem desse repertório (e.g., Matos, et al., 2006; Sidman, 1971; Sidman \& Tailby, 1982); (2) no desenvolvimento de procedimentos de avaliação das habilidades envolvidas na rede, que permitem identificar competências e dificuldades de estudantes individuais (eg., Fonseca, 1997) com finalidades diagnósticas; (3) no desenvolvimento e avaliação de procedimentos eficazes de ensino (de Souza \& de Rose, 2006; Matos et al., 2006); e (4) no planejamento de um currículo para estabelecer em alunos principiantes, com ou sem história de fracasso escolar, um repertório de leitura (de Souza, de Rose, Hanna, Calcagno, \& Galvão, 2004; Melchiori, de Souza, \& de Rose, 2000).

Diversos processos comportamentais estão presentes nas etapas de aquisição de leitura, como discriminações simples e modelagem de respostas vocais envolvidas na leitura oral, discriminações condicionais, presentes na aquisição de relações arbitrárias entre palavras, sons e desenhos (ou outros referentes) e a formação de classes de estímulos equivalentes (Sidman \& Tailby, 1982) que incluem palavras escritas, palavras faladas e os referentes no ambiente (que são simulados, na investigação experimental, por figuras). Quando esses estímulos se tornam equivalentes, as relações entre eles apresentam as propriedades de simetria, transitividade e reflexividade e definem, segundo Sidman (1994), a leitura com compreensão.

Além de ler com compreensão, no entanto, o estágio de leitura almejado pela escola é o de leitura combinatória ou recombinativa, ou seja, a habilidade de ler e compreender qualquer palavra da língua (não apenas o que foi diretamente ensinado), a partir da combinação e recombinação do reduzido conjunto de símbolos do alfabeto.

O termo generalização recombinativa ${ }^{3}$ descreve novas combinações de unidades linguísticas previamente aprendidas (Goldstein, 1983, 1993; Wetherby \& Striefel, 1978): elementos de estímulos componentes de relações aprendidas são recombinados em novas configurações e cada componente continua a exercer controle preciso e apropriado sobre o componente correspondente das respostas.

3 O termo generalização é controvertido no contexto de controle discriminativo por elementos de estímulos (Alessi, 1987), verbais ou não verbais; por essa razão, este texto emprega as expressões leitura recombinativa e comportamento textual emergente. 
Na leitura, o repertório recombinativo depende do estabelecimento de controle das respostas por elementos gráficos menores do que a unidade linguística com significado (palavra). Unidades textuais com diferentes extensões têm sido utilizadas em diferentes métodos de ensino de leitura (sentenças, palavras, sílabas e fonemas), não sem intensos debates sobre que unidades gerariam melhores resultados (e.g., Adams, 1994; Bishop, 1964; Snow, Griffin, \& Burns, 2005). O sucesso de programas de ensino depende de muitos fatores, além da extensão dos estímulos textuais; mas, no que concerne aos processos básicos envolvidos, a literatura científica tem como bem estabelecido o fato de que a habilidade de recombinar unidades intra-silábicas é crítica para a aprendizagem de leitura de palavras novas (Mueller et al., 2000, p. 516).

Leitura recombinativa com compreensão caracteriza o repertório de um leitor que é capaz de: (a) produzir respostas vocais na presença de qualquer novo texto escrito em sua língua; e (b) relacionar os eventos, ações, objetos, pessoas etc. que correspondem ao texto e às palavras lidas. Estas competências são essenciais para um leitor competente e independente.

Metodologias de ensino que visam instalar a rede de relações de equivalência de estímulos que caracterizam a leitura com compreensão têm sido bem-sucedidas com pré-escolares (Hubner, Matos, \& Serra, 2002; Matos et al., 1997, 1999, 2006; Melchiori et al., 2000; Mueller et al., 2000), adultos analfabetos, indivíduos com deficits intelectuais e crianças com história de fracasso escolar (de Rose et al., 1996; Melchiori et al., 2000). Esses estudos utilizaram palavras como a unidade textual ensinada e a leitura recombinativa emergiu à medida que o treino avançou e que o número de palavras ensinadas aumentou. Contudo, o grau de leitura recombinativa variou entre os participantes e alguns deles não foram capazes de ler palavras novas mesmo depois de terem aprendido a ler mais de 50 palavras. Essa variabilidade na quantidade de leitura recombinativa sugere que $o$ controle por unidades menores pode se desenvolver a partir do ensino de palavras inteiras, mas esta não é uma condição suficiente para assegurar plenamente leitura recombinativa sistemática e estável. Vários desses estudos têm adicionado, aos procedimentos de ensino de palavras inteiras, manipulações experimentais visando favorecer o desenvolvimento de controle por relações som-texto com unidades menores que a palavra. As manipulações realizadas incluem: 1) a oralização escandida, que requer a emissão de respostas vocais correspondentes às sílabas (Matos et al., 1999, 2006); 2), o emparelhamento com o modelo com atraso e construção de resposta (CRMTS), que requer a escolha de letras correspondentes ao modelo escrito ou ditado, colocando o aprendiz em contato com cada elemento impresso e com a sequência dos elementos na palavra inteira (de Rose et al., 1996; Hanna, de Souza, de Rose, \& Fonseca., 2004; Stromer \& Mackay, 1992);3) o emparelhamento com o modelo entre sílabas impressas e sílabas ditadas, sobreposto ao emparelhamento com palavras (de Souza, de 
Rose, Faleiros, Bortoloti, Hanna, \& Mcllvane, 2009b). Esses estudos também selecionaram palavras de ensino que permitiam algum grau de sobreposição entre elementos de palavras ensinadas, isto é, o próprio procedimento envolvia recombinação de estímulos (eg., BOCA/CABO;VACA/BOLO/CAVALO/; PATO/PIPA/GATO), o que pode ter favorecido o desenvolvimento de abstração, necessário à leitura recombinativa.

Uma das dificuldades na interpretação dos resultados desses estudos é que o uso de palavras da língua pode envolver diferentes histórias pré-experimentais com os estímulos empregados. Além disso, em estudos com escolares é difícil distinguir entre efeitos independentes das variáveis experimentais e da instrução escolar.

Visando controlar a interferência potencial desses fatores, foi desenvolvido um pseudoalfabeto que caracteriza um sistema linguístico em miniatura (MLS) e que vem sendo empregado em uma série de estudos que simulam uma tarefa de aprendizagem de leitura em uma nova língua. As palavras faladas são inventadas e os símbolos que representam os sons são inéditos (Rocha \& Hanna, 1996a, 1996b; Albuquerque \& Hanna, 2001; Hanna, Kohlsdorf, Quinteiro, Fava, de Souza, \& de Rose., 2008; Hanna, Kohlsdorf, Quinteiro, Melo, de Souza, de Rose \& Mcllvane, submetido). Esse tipo de sistema, introduzido por Esper (1925) na investigação de processos linguísticos, consiste de "um conjunto de estímulos especialmente criados para propósitos experimentais, que varia ao longo de uma ou mais dimensões (eg., forma, letra, posição) e um conjunto de respostas específicas, requeridas na presença de tais estímulos" (Foss, 1968). No sistema usado por Hanna et al., o alfabeto inventado (conjunto de símbolos gráficos desconhecidos, cada símbolo correspondendo a um único som) permite controlar a história com os estímulos experimentais e manipular mais livremente a estrutura dos estímulos utilizados (número de sílabas e letras, forma de recombinar as sílabas e letras para formar palavras, tamanho da palavra etc.). Estudos realizados com participantes com diferentes histórias e repertórios de leitura (crianças alfabetizadas, não alfabetizadas e universitários) ensinaram correspondências entre pseudopalavras ditadas, figuras abstratas e palavras impressas e avaliaram os repertórios emergentes analisados por Sidman (1971): leitura oral, leitura com compreensão e leitura receptivo-auditiva. Os resultados mostraram aprendizagem das relações ensinadas e emergência de novas relações envolvendo as palavras ensinadas. Esses estudos também manipularam cuidadosamente os elementos componentes das palavras ensinadas e avaliaram a emergência de leitura de palavras novas, formadas pela recombinação de elementos de palavras ensinadas. Os resultados variaram, dependendo da quantidade de palavras ensinadas e do grau de sobreposição ou de recombinação das mesmas sílabas em diferentes palavras e em diferentes posições (Albuquerque \& Hanna, 2001; Hanna et al., 2008; Hanna et al., submetido; Quinteiro, 2003; Rocha \& Hanna, 1996a, 1996b). 
Na mesma linha de investigação, o presente estudo pretendeu analisar os efeitos de duas variáveis que têm sido sugeridas como importantes para o desenvolvimento de controle de estímulos por elementos de estímulos compostos, e que poderiam, portanto, facilitar também a leitura recombinativa: (a) o grau de similaridade ou de diferença entre estímulos positivos e negativos nas tarefas de pareamento ao modelo empregadas para ensinar as discriminações básicas e (b) a extensão da unidade textual ensinada. $O$ Experimento 1 investigou o efeito do grau de similaridade entre as palavras ( $75 \%$ ou $25 \%$ de elementos em comum) utilizadas no treino discriminativo sobre o desenvolvimento de leitura recombinativa. O Experimento 2 ensinou relações com unidade textuais menores que a palavra (sílaba ou letra) antes de ensinar as relações entre palavras faladas e impressas, visando verificar os possíveis efeitos dessa manipulação sobre o desenvolvimento de leitura de palavras novas.

\section{Experimento 1}

A possibilidade de controle seletivo por apenas parte da palavra, quando se utiliza a palavra como unidade textual de ensino, pode explicar desempenhos baixos ou variáveis em testes com palavras formadas pela recombinação de sílabas ou letras de palavras ensinadas (Adams, 1994; de Rose et al., 1996).

Allen e Fuqua (1985) mostraram que uma forma de minimizar o controle de estímulos restrito, no ensino de discriminações condicionais com estímulos complexos, consiste em manipular os estímulos, de modo que eles apresentem diferenças mínimas entre si (por exemplo, em estímulos com quatro elementos, a diferença residiria em apenas um deles, enquanto os outros três elementos seriam iguais em todos os estímulos).

Birnie-Selwyn e Guerin (1997) aplicaram este princípio ao estudo de soletração, manipulando duas condições no ensino de palavras da língua inglesa. Na Condição Diferenças Múltiplas, em um treino de emparelhamento com o modelo (MTS) auditivo-visual, as palavras impressas apresentadas como estímulos de comparação negativos (S-) diferiam em múltiplos aspectos da palavra que funcionava como S+. Na Condição Diferenças Crítica as palavras S- diferiam em apenas um aspecto em comparação com a palavra S+.Depois de estabelecida a linha de base, o teste de soletração requeria que a criança selecionasse e sequenciasse as letras que compunham a palavra ditada como modelo. Durante o ensino das relações condicionais todos os participantes mostraram melhor desempenho na Condição Diferenças Múltiplas. Porém, nos Testes de Soletração, todos os participantes apresentaram um melhor desempenho após o ensino na Condição Diferenças Crítica. Esses resultados sugerem que a aquisição de discriminações condicionais com estímulos mais similares nos seus aspectos irrelevantes é mais eficiente para gerar controle pelos elementos ou características re- 
levantes: enquanto a condição com menor similaridade possibilita a ocorrência de respostas sob controle de partes do estímulo, a condição com diferença mínima, em aspectos críticos, requer olhar para todo o estímulo, o que pode favorecer o controle por todas as letras da palavra.

Albuquerque (2001) manipulou o grau de similaridade entre pseudopalavras empregadas como S- e S+ em treinos de discriminação condicional com crianças e observou desempenho preciso, com poucos erros no ensino de relações entre pseudopalavras ditadas e escritas, especialmente na Condição Diferenças Múltiplas. Porém, os escores nos testes de leitura recombinativa foram muito baixos e variáveis, independente do grau de similaridade entre as palavras empregadas. Os resultados sugeriram a necessidade de controle de variáveis, como a quantidade de palavras ensinadas, a quantidade de tentativas por sessão, o valor reforçador das consequências empregadas. Essas sugestões foram incorporadas em um procedimento que vem se mostrando adequado para o propósito de investigar a aprendizagem e a emergência de leitura recombinativa com o Sistema Linguístico em Miniatura (eg., Hanna et al., 2008). Este procedimento foi empregado neste estudo que visou replicar, com universitários, o estudo de Albuquerque (2001), manipulando o grau de similaridade entre palavras impressas apresentadas como estímulos de comparação nas tarefas de emparelhamento com o modelo. Todas as palavras tinham quatro letras e cada comparação negativo diferia do de comparação positivo em uma (diferença crítica) letra ou em três letras (diferenças múltiplas).

\section{Método}

\section{Participantes}

Participaram deste experimento oito estudantes da Universidade de Brasília, com idades entre 18 e 22 anos, recrutados nas salas das aulas da disciplina Introdução à Psicologia, ministrada para diferentes cursos. Foram selecionados estudantes da área de Ciências Humanas, dos cursos de Medicina, Nutrição e Serviço Social, que não haviam participado de disciplinas ou pesquisas que abordavam temas relacionados a este estudo (equivalência de estímulos, desempenho recombinativo). Os participantes eram informados de que se tratava de uma investigação sobre comportamento simbólico; eram informados, também, sobre a frequência e a duração estimada das sessões experimentais. Os interessados assinaram um Termo de Consentimento Livre e Esclarecido, preencheram um formulário com informações pessoais e sobre o domínio de língua estrangeira. Antes da primeira sessão experimental o experimentador solicitava a cada participante que não comentasse com outros participantes da pesquisa suas impressões e experiências durante o experimento. 


\section{Situação, Material e Equipamentos}

Sessões com participantes individuais, com duração aproximada de 20 minutos, eram realizadas em uma sala de aproximadamente $6 \mathrm{~m}^{2}$, localizada no Anexo do Laboratório de Aprendizagem Humana do Instituto de Psicologia da Universidade de Brasília. A sala tinha isolamento acústico, sistema artificial de entrada e saída de ar e era mobiliada com duas mesas para computador, duas cadeiras, um banco e dois armários. Sobre uma das mesas foi instalado um computador Macintosh Performa 6230CD completo (monitor, teclado, mouse e estabilizador). Em todas as sessões estavam presentes o experimentador e um observador devidamente treinado para operar os equipamentos e registrar as respostas orais. Para a apresentação das tarefas experimentais e o registro de dados foi empregado o software MTS v. 11.6.7. (Dube, 1991). Respostas de escolha eram registradas automaticamente. A leitura oral de palavras era gravada em um gravador portátil colocado sobre a mesa e registrada pelo experimentador e pelo observador em protocolos que incluíam a listagem sequencial de tentativas que requeriam leitura.

\section{Estímulos}

Os estímulos consistiram de palavras faladas (A) e palavras escritas com um pseudoalfabeto (C). As palavras eram dissílabas (consoante + vogal + consoante + vogal ou CVCV) e nenhuma palavra com função de S+ tinha significado na língua portuguesa. As letras do pseudoalfabeto, apresentadas na Figura 1, foram criadas no programa Fontographer 4.1 (Macromedia Inc) a partir do alfabeto grego, e mantinham uma correspondência um a um com os fonemas $/ \mathrm{a} /, / \mathrm{\varepsilon} /, / \mathrm{i} /, / \mathrm{l} /, / \mathrm{lb} /, / \mathrm{f} /, / \mathrm{l} / \mathrm{e} / \mathrm{n} /$. As sílabas utilizadas na formação das palavras de treino eram NI, BO, LE e FA. Cada sílaba ocorria tanto no início quanto no final das palavras ao longo dos treinos. As palavras utilizadas nos testes de recombinação continham pelo menos uma sílaba não treinada formada pela recombinação das letras das palavras de treino. Todas as vogais das palavras faladas eram pronunciadas de forma aberta. Todas as palavras eram pronunciadas como oxítonas. Os estímulos reforçadores consistiam de animações e sons emitidos pelo computador, que constam do banco de dados do software MTS.

\section{Procedimento}

O procedimento teve a seguinte sequência de etapas: Pré-treino, Ensino e testes parciais da Condição 1, Pós-teste da Condição 1, Ensino e testes parciais da Condição 2, Pós-teste da Condição 2. Para quatro participantes a Condição 1 foi a de Diferenças Múltiplas e a Condição 2 foi a de Diferença Crítica; para os outros quatro, a ordem foi invertida. Cada Condição vigorou durante três ciclos de treinos e testes parciais. Em cada treino eram ensinadas as relações com duas palavras. A Tabela 1 apresenta a sequência de treinos e testes realizados. 


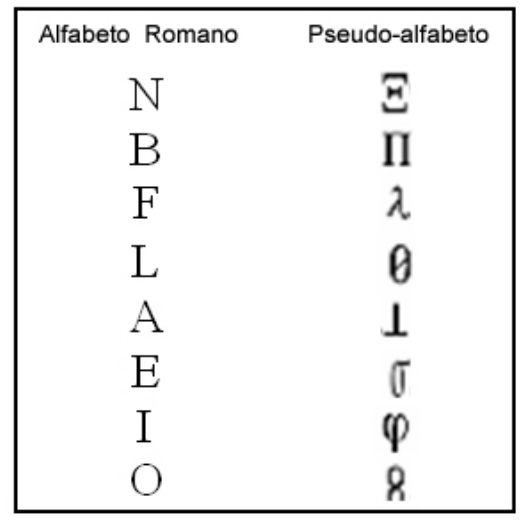

Figura 1.Correspondência entre as letras do pseudoalfabeto e do alfabeto romano.

Tabela 1. Treinos e Testes realizados em cada ciclo e condição do Experimento 1.

\begin{tabular}{|c|c|c|c|}
\hline Ciclos & Condição & $\begin{array}{c}\text { Etapas de Cada Ciclo } \\
\text { Experimental }\end{array}$ & $\begin{array}{c}\text { Relação Ensinada/ } \\
\text { Testada }\end{array}$ \\
\hline \multirow[t]{7}{*}{1 a 3} & Diferença Crítica* & Treino AC & $\begin{array}{l}\text { Pareamento palavra } \\
\text { ditada-palavra impressa }\end{array}$ \\
\hline & & Treino CD & $\begin{array}{l}\text { Nomeação de palavra } \\
\text { impressa }\end{array}$ \\
\hline & & Teste Parcial de & Nomeação de palavra \\
\hline & & Recombinação C'D & impressa \\
\hline & & Teste Parcial de & Pareamento palavra \\
\hline & & Recombinação $A^{\prime} C^{\prime}$ & ditada-palavra impressa \\
\hline & & Pós-Teste C'D da Condição 1 & $\begin{array}{l}\text { Pareamento palavra } \\
\text { ditada-palavra impressa }\end{array}$ \\
\hline \multirow[t]{7}{*}{4 a 6} & $\begin{array}{l}\text { Diferenças } \\
\text { Múltiplas* }\end{array}$ & Treino AC & $\begin{array}{l}\text { Pareamento palavra } \\
\text { ditada-palavra impressa }\end{array}$ \\
\hline & & Treino CD & $\begin{array}{l}\text { Nomeação de palavra } \\
\text { impressa }\end{array}$ \\
\hline & & Teste Parcial de & Nomeação de palavra \\
\hline & & Recombinação C'D & impressa \\
\hline & & Teste Parcial de & Pareamento palavra \\
\hline & & Recombinação $A^{\prime} C^{\prime}$ & ditada-palavra impressa \\
\hline & & Pós-Teste C'D da Condição 2 & $\begin{array}{l}\text { Pareamento palavra } \\
\text { ditada-palavra impressa }\end{array}$ \\
\hline
\end{tabular}

* A ordem de apresentação das condições foi balanceada entre os participantes 
Tabela 2. Palavras utilizadas como S+e respectivos S-, em cada ciclo da Condição Diferença Crítica do Experimento 1.

\begin{tabular}{|c|c|c|c|c|c|c|c|c|}
\hline Ciclos & S+ & S- & S- & S- & $\mathrm{S}+$ & S- & S- & S- \\
\hline \multirow[t]{4}{*}{1} & nibo & fibo & libo & bibo & Fale & nale & bale & lale \\
\hline & & nifo & nilo & nino & & fane & fabe & fafe \\
\hline & & nabo & nebo & nobo & & file & fole & fele \\
\hline & & niba & nibe & nibi & & fali & falo & fala \\
\hline \multirow[t]{4}{*}{2} & bofa & nofa & lofa & fofa & Leni & beni & feni & neni \\
\hline & & bona & bola & boba & & lebi & lefi & leli \\
\hline & & befa & bifa & bafa & & Iani & Ioni & lini \\
\hline & & bofe & bofi & bofo & & lena & leno & lene \\
\hline \multirow[t]{4}{*}{3} & lebo & nebo & febo & bebo & Fani & bani & Iani & nani \\
\hline & & lefo & leno & lelo & & fabi & fali & fafi \\
\hline & & labo & libo & lobo & & feni & foni & fini \\
\hline & & lebi & leba & lebe & & fane & fano & \\
\hline \multirow[t]{4}{*}{4} & boni & foni & Ioni & noni & Lefa & nefa & befa & fefa \\
\hline & & bofi & boli & bobi & & lena & leba & lela \\
\hline & & bani & beni & bini & & lifa & lofa & lafa \\
\hline & & bona & bone & bono & & lefi & lefo & lefe \\
\hline \multirow[t]{4}{*}{5} & fabo & nabo & labo & babo & Nile & bile & file & lile \\
\hline & & fano & falo & fafo & & nibe & nife & nine \\
\hline & & febo & fibo & fobo & & nale & nole & nele \\
\hline & & fabe & fabi & faba & & nila & nilo & nili \\
\hline \multirow[t]{4}{*}{6} & bole & nole & fole & lole & Nifa & bifa & lifa & fifa \\
\hline & & bone & bofe & bobe & & niba & nila & nina \\
\hline & & bale & bile & bele & & nefa & nofa & nafa \\
\hline & & bola & boli & bolo & & nife & nifo & nifi \\
\hline
\end{tabular}

\section{Pré-treino}

Esta etapa visou reduzir os efeitos de novidade da tarefa sobre a aquisição das relações a serem ensinadas e foi realizada com estímulos diferentes dos empregados nas fases de ensino e testes. A tarefa era emparelhamento com o modelo visual-visual; os estímulos-modelo eram dois quadrados pre- 
enchidos com padrões em branco e preto e os estímulos de comparação eram triângulos ou quadrados coloridos (azul ou vermelho). Na presença do modelo 1, a escolha da cor vermelha (independente da forma) era seguida por consequências de acerto (estrelas na tela, uma sequência de tons musicais ou a palavra "correct"). A escolha da outra cor era seguida por uma tela preta por $3 \mathrm{~s}$. O modelo 2 foi emparelhado com a cor azul.

Procedimento geral de ensino

O procedimento geral consistiu de três ciclos de treinos e testes parciais em cada condição experimental, seguidos por testes extensivos (ver Tabela 1). Três ciclos foram realizados na Condição Diferenças Crítica (DC) e três na Condição Diferenças Múltiplas (DM).

$\mathrm{Na}$ Condição DC todas as palavras apresentadas como S- diferiam em apenas uma letra da palavra apresentada como $\mathrm{S}+$ (três das quatro letras, ou $75 \%$, eram iguais). Na Condição DM, os S- diferiam do S+ em três letras (1 das 4 letras era igual). As palavras utilizadas como estímulos S+e S- em cada ciclo de cada condição experimental são listadas nas Tabelas 2 e 3.

Tabela 3. Palavras utilizadas como $\mathrm{S}+$ e respectivos $\mathrm{S}-$, em cada ciclo da Condição Diferenças Múltiplas do Experimento 1.

\begin{tabular}{|c|c|c|c|c|c|c|}
\hline Ciclos & S+ & S- & S- & S+ & S- & S- \\
\hline \multirow[t]{2}{*}{1} & nibo & nefa & lifa & fale & fibo & nabo \\
\hline & & fabe & falo & & boli & bone \\
\hline \multirow[t]{2}{*}{2} & bofa & bile & nole & leni & labo & febo \\
\hline & & lefi & lena & & bona & bofi \\
\hline \multirow[t]{2}{*}{3} & lebo & Iani & feni & fani & fole & bale \\
\hline & & niba & nifo & & leno & lebi \\
\hline \multirow[t]{2}{*}{4} & boni & befa & lofa & lefa & Ioni & beni \\
\hline & & fane & fali & & nifo & niba \\
\hline \multirow[t]{2}{*}{5} & fabo & file & nale & nile & nofa & bifa \\
\hline & & lebi & leno & & falo & fabe \\
\hline \multirow[t]{2}{*}{6} & bole & bani & foni & nifa & nebo & libo \\
\hline & & nila & nife & & bofe & bola \\
\hline
\end{tabular}


Em cada ciclo eram ensinadas duas relações entre palavras ditadas e palavras impressas com o pseudoalfabeto e a leitura oral das duas palavras (Treino AC/CD). As duas palavras dissílabas combinavam as sílabas NI, $\mathrm{BO}$, FA e LE, garantindo-se que, em cada condição experimental, as sílabas ocorressem no início e no final das palavras (Tabelas 2 e 3). Após o Treino $A C / C D$, eram realizados os Testes Parciais que avaliavam a leitura oral de quatro novas palavras (recombinadas) e a seleção das quatro palavras impressas na presença dos respectivos modelos ditados (Tabela 4). Os estímulos novos são indicados como pertencentes aos conjuntos $A^{\prime}$ e $C^{\prime}$. Os Testes Parciais ( $A^{\prime} C^{\prime}$ e $C^{\prime} D$ ) finalizavam cada ciclo.

Ao final do terceiro ciclo de cada condição experimental era administrado um teste de nomeação de palavras (Pós-teste $C D$ ), que avaliava todas as palavras ensinadas naquela condição (e na condição precedente, no caso da Condição 2) e, também, um conjunto de palavras de recombinação. O Pós-teste CD após a Condição 1 avaliou 18 palavras e o Pós-teste CD após a Condição 2 avaliou 36 palavras.

Treino AC/CD. O Treino AC/CD envolvia tentativas de pareamento e de nomeação ou leitura oral das palavras impressas. As tentativas de emparelhamento iniciavam com a apresentação de um quadrado no centro da tela e um estímulo auditivo (A). Uma resposta (clicar com o mouse, com a seta posicionada no quadrado) era seguida pela apresentação de três estímulos de comparação escritos (C). A seleção da palavra definida como S+ produzia consequências de acerto. $\mathrm{O}$ emparelhamento foi ensinado gradualmente. Na primeira tentativa era apresentado apenas o estímulo correto (S+). O número de comparações aumentava progressivamente até três (uma palavra correta e duas incorretas) ao longo do treino. A posição dos estímulos de comparação variava a cada tentativa. A primeira palavra era treinada até o participante alcançar $100 \%$ de acertos em um bloco de três tentativas de pareamento com dois estímulos de comparação e 100\% de acertos em um bloco de duas tentativas de leitura. Então, introduziase a segunda palavra e essa era treinada da mesma forma que a primeira. Após o treino da segunda palavra, era realizado um bloco com tentativas de pareamento ao modelo com os dois estímulos-modelo alternando-se de forma assistemática; $100 \%$ de acertos nesse bloco de seis tentativas e $100 \%$ de acertos no bloco subsequente com quatro tentativas de nomeação eram utilizados como critério para finalizar o treino. Nas tentativas de nomeação, apresentava-se o desenho de um rosto no centro da tela representando que a tarefa requeria a nomeação da palavra, que era seguido pela apresentação de um estímulo impresso (C) na parte centro-inferior da tela. Na primeira tentativa o experimentador instruía o participante a "nomear os símbolos apresentados na tela". Respostas corretas eram seguidas por consequências de acerto e respostas incorretas eram seguidas por um blackout (tela preta) de $3 \mathrm{~s}$, seguido pela repetição da tentativa. 
Tabela 4. Palavras utilizadas como S+e S- nos testes parciais de recombinação AC em cada ciclo do Experimento 1.As palavras $S+$ também eram apresentadas nos testes parciais de leitura oral (CD).

\begin{tabular}{|c|c|c|c|c|c|c|}
\hline \multirow[t]{2}{*}{ Ciclos } & \multicolumn{3}{|c|}{ 1a Seqüência de Apresentação } & \multicolumn{3}{|c|}{ 2a Seqüência de Apresentação } \\
\hline & $\mathrm{S}+$ & S- & S- & $\mathrm{S}+$ & S- & S- \\
\hline \multirow[t]{4}{*}{1} & nibe & fibe & nobe & Lofi & lobi & lofa \\
\hline & falo & balo & felo & Bena & befa & beno \\
\hline & lofi & bofi & lafi & Nibe & niba & nife \\
\hline & bena & bana & lena & Falo & fali & fano \\
\hline \multirow[t]{4}{*}{2} & bofi & lofi & bafi & Nale & nalo & nabe \\
\hline & leno & lano & beno & Fiba & fifa & fibo \\
\hline & nale & bale & nole & bofi & bofe & boni \\
\hline & fiba & feba & niba & Leno & leni & lefo \\
\hline \multirow[t]{4}{*}{3} & leba & neba & liba & Nofa & nofo & noba \\
\hline & fena & fina & bena & Bila & bifa & bilo \\
\hline & nofa & bofa & nefa & Leba & lebe & lefa \\
\hline & bila & bala & nila & Fena & feni & fela \\
\hline \multirow[t]{4}{*}{4} & bona & fona & bena & Lefi & lefo & lebi \\
\hline & fola & fela & nola & Bane & bafe & bano \\
\hline & lefi & nefi & lofi & Bona & boni & bofa \\
\hline & bane & bine & nane & Fola & foli & foba \\
\hline \multirow[t]{4}{*}{5} & fabe & nabe & fibe & Nilo & nila & nifo \\
\hline & lafe & lefe & bafe & Bile & bine & bila \\
\hline & nilo & bilo & nalo & Fabe & fabo & fane \\
\hline & bile & bole & lile & Lafe & lafo & labe \\
\hline \multirow[t]{4}{*}{6} & febi & nebi & fobi & Lano & lane & labo \\
\hline & bafi & bofi & fafi & Nole & nofe & nola \\
\hline & Iano & bano & leno & Febi & febo & feni \\
\hline & nole & nale & bole & Bafi & bafa & bani \\
\hline
\end{tabular}


Os Treinos AC/CD iniciavam-se com um pré-teste de leitura das duas palavras. Cada palavra era apresentada individualmente (com a figura do rosto) e o participante era instruído a dizer o nome dos símbolos. Caso o participante errasse pelo menos uma palavra, o Treino AC/CD era iniciado; após o bloco de treino a leitura era novamente avaliada (pós-teste da sessão). Caso o participante acertasse as duas palavras (no pré ou no pósteste), o Treino AC/CD era conduzido sob reforçamento intermitente, em preparação para os Testes Parciais. Empregou-se o esquema de razão variável 2, ou seja, metade das respostas corretas eram seguidas por reforço e a distribuição das consequências ao longo das tentativas era variada.

Testes Parciais. Em cada ciclo eram realizados, após o treino, dois tipos de testes parciais de recombinação: o Teste $C^{\prime} D$, que requeria leitura de uma palavra de recombinação, seguido pelo Teste $A^{\prime} C^{\prime}$, em que uma palavra de recombinação era ditada e os estímulos de comparação eram palavras impressas recombinadas (um $\mathrm{S}+\mathrm{e}$ dois $\mathrm{S}$-). Ambos os testes avaliavam as mesmas quatro palavras de recombinação, isto é, as palavras $\mathrm{S}+$ no Teste $A^{\prime} C^{\prime}$ eram as mesmas do teste $C^{\prime} D$ (Tabela 4). Os Testes C'D e os Testes $A^{\prime} C^{\prime}$ eram compostos por oito tentativas (duas com cada palavra), apresentando as palavras de recombinação em duas sequências distintas (ver Tabela 4).

Pós-teste C'D. Após o encerramento do terceiro ciclo de cada condição experimental, avaliava-se a nomeação de todas as palavras escritas com o pseudoalfabeto utilizadas até então nas sessões de treino e testes. Cada palavra era apresentada na tela do monitor separadamente e o participante era instruído a nomear os símbolos. Respostas certas ou erradas eram seguidas pela próxima palavra na tela. No Pós-teste da Condição 1 foi avaliada a leitura de 18 palavras, 6 de treino e 12 novas; no Pós-teste da Condição 2 foram avaliadas 36 palavras, as 12 de treino e 24 novas.

\section{Registro de dados de observação e cálculo de acordo}

Todas as respostas de nomeação eram gravadas e registradas pelo experimentador e pelo observador. Quando o participante apresentava mais de uma resposta para uma mesma palavra, era registrada apenas a última. O observador não tinha acesso ao registro do experimentador, e vice-versa. $O$ índice de acordo entre os registros foi calculado dividindose o número de acordos pelo total de registros da sessão. Nas tentativas em que havia desacordo entre observador e experimentador, uma terceira pessoa escutava realizava o registro a partir da gravação. Para fins de análise era considerada a resposta com dois registros iguais.

\section{Resultados e Discussão}

O índice de acordo das respostas de nomeação foi de $99,6 \%$ de um total de 1654 tentativas. 
Todos os participantes aprenderam as relações ensinadas nos treinos $A C / C D$, tanto na condição DC quanto na condição DM. A Figura 2 mostra o número médio de tentativas para atingir o critério de aprendizagem $(100 \%$ de acertos nas últimas quatro tentativas) nos ciclos de cada condição experimental para cada participante. As linhas verticais representam um desvio-padrão da média. As barras cinza escuro representam o resultado na Condição DC e as barras cinza claro, na Condição DM. Os resultados dos participantes que iniciaram o procedimento pela Condição DC encontramse à esquerda e os que iniciaram pela Condição DM, à direita. De forma geral, o número de tentativas para atingir o critério de aprendizagem foi maior na Condição DC que na Condição DM (com exceção de Wilson). O número de tentativas ao longo dos ciclos da Condição DC para os participantes que iniciaram por esta condição apresentou tendência decrescente (resultados não mostrados na figura). Para esses participantes a quantidade de treino necessária para aprender as relações no último ciclo da Condição DC foi semelhante à dos ciclos da Condição DM. A Condição DM mostrou-se mais eficiente (menor número de erros e tentativas) para ensinar as relações entre palavras ditadas e escritas para a maioria dos participantes. $O$ melhor desempenho na Condição DM do que na Condição DC nas tarefas de emparelhamento replica resultados de estudos prévios (Allen \& Fuqua, 1985; Birnie-Selwyn \& Guerin, 1997) que mostraram maior rapidez na aquisição das discriminações quando os estímulos positivos e negativos apresentavam menos elementos em comum. $O$ presente experimento mostrou, entretanto, que o aumento do número de discriminações ensinadas com o mesmo procedimento pode reduzir essa diferença entre os resultados, diminuindo a quantidade de treino necessária na Condição DC.

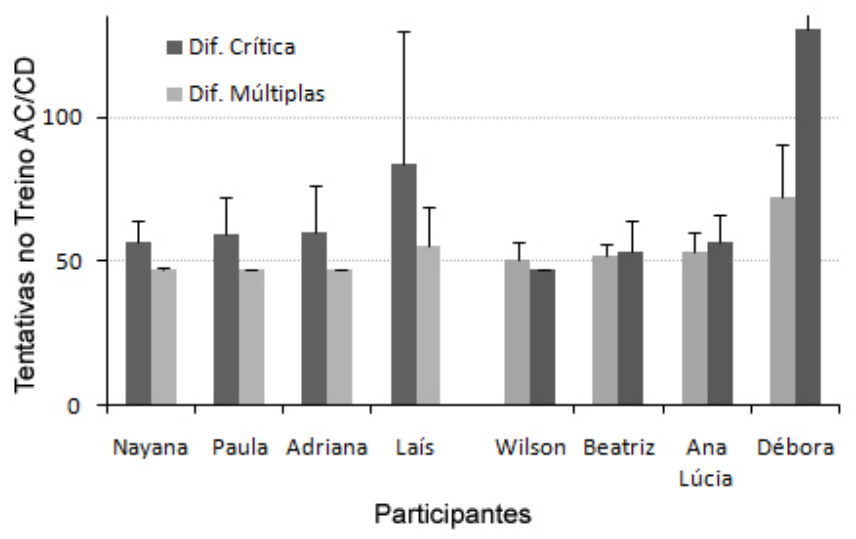

Figura 2. Número médio de tentativas necessárias para atingir o critério de aprendizagem no Treino AC/CD nos ciclos das Condições Diferença Crítica e Diferenças Múltiplas, para cada participante do Experimento 1. Linhas verticais representam um desvio-padrão da média. 


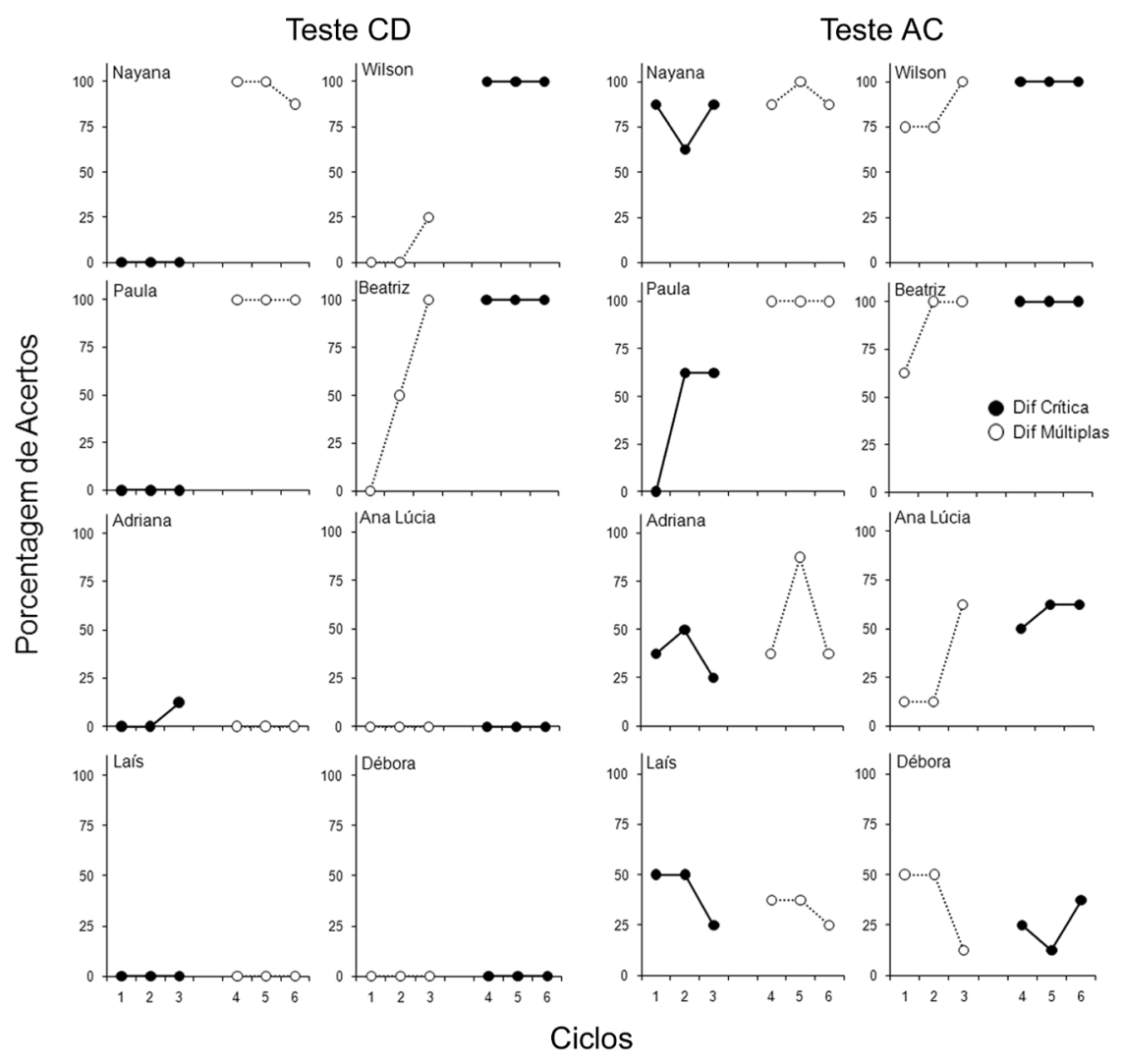

Figura 3. Porcentagem de acertos nos Testes Parciais CD (textual de palavras) e AC (seleção de palavra impressa correspondente a palavra falada) dos ciclos da Condição Diferença Crítica (símbolos cheios) e dos ciclos da Condição Diferenças Múltiplas (símbolos vazios) para cada participante do Experimento 1.

A Figura 3 mostra o desempenho dos participantes nos Testes Parciais de recombinação $C^{\prime} D$ (gráficos à esquerda na figura) e $A^{\prime} C^{\prime}$ (gráficos à direita na figura) nos ciclos experimentais de cada condição. Os círculos cheios representam o desempenho na Condição DC e os círculos vazios, na Condição DM.

Metade dos participantes (Wilson, Nayana, Paula e Beatriz) atingiu o nível máximo de desempenho em leitura oral ( $\left.C^{\prime} D\right)$ nos últimos ciclos do experimento. Dentre estes participantes, dois iniciaram pela condição DC (Nayana e Paula) e dois iniciaram pela condição DM (Wilson e Beatriz). Os participantes com baixos escores de leitura recombinativa também se distribuíram igualmente entre as duas condições experimentais.

Os participantes que desenvolveram leitura recombinativa plena apresentaram algumas diferenças segundo a condição experimental a 
que foram submetidos. As participantes Nayana e Paula, que iniciaram o experimento pela Condição $\mathrm{DC}$, não apresentaram leitura recombinativa até o terceiro ciclo experimental. A partir do Ciclo 4 (o primeiro sob a Condição 2, DM), estas participantes apresentaram leitura recombinativa com alta porcentagem de acertos. Os participantes Wilson e Beatriz, que iniciaram pela Condição DM, apresentaram leitura recombinativa nesta primeira condição: Beatriz a partir do Ciclo 2 (com 50\% de acertos) e Wilson a partir do Ciclo 3 (com $25 \%$ de acertos). A participante Beatriz foi a única a desenvolver leitura recombinativa plena ainda sob esta primeira condição (100\% de acertos no Ciclo 3). Ao passar para a condição DC, estes dois participantes mantiveram uma porcentagem de acertos de $100 \%$ ao longo dos três ciclos experimentais.

Observou-se, para os participantes que desenvolveram leitura recombinativa plena, um aumento de acertos à medida que novas palavras eram ensinadas. Os resultados são insuficientes para sugerir efeitos das condições experimentais, ressaltando-se apenas a sistematicidade do efeito da quantidade de palavras ensinadas para a emergência de leitura recombinativa.

A Figura 3 mostra, também, nos painéis à direita, os desempenhos nos Testes $A^{\prime} C^{\prime}$ (pareamento ao modelo com palavras novas), aplicados ao longo dos ciclos experimentais. Nestes testes, que avaliavam leitura receptivo-auditiva (Sidman, 1971), os desempenhos foram, em geral, mais altos do que no Teste C'D, mas observa-se a mesma tendência: a porcentagem de acertos aumentou à medida que eram ensinadas novas palavras. Entre os participantes que desenvolveram leitura recombinativa, a porcentagem de acertos foi próxima de $100 \%$ nos três últimos ciclos $(4,5$, e 6$)$, independente da condição experimental. Nos três primeiros ciclos a porcentagem de acertos destes mesmos participantes mostrou-se superior para os que se encontravam sob a Condição DM. Os demais participantes apresentaram escores ligeiramente acima do acaso, mas não mostraram progressos ao longo dos ciclos, exceto Ana Lucia, nos quatro últimos ciclos. Esses resultados sugerem o desenvolvimento incipiente de algum controle por elementos textuais, porém insuficiente para assegurar desempenho consistente mesmo nas tarefas de emparelhamento.

A Figura 4 mostra o desempenho dos participantes nos Pós-testes C'D realizados após cada condição experimental. As colunas com padrão de preenchimento escuro representam o desempenho na Condição DC e as colunas com padrão de preenchimento claro representam o desempenho na Condição DM. Resultados dos participantes que começaram pela Condição DC estão apresentados à esquerda e os dos que iniciaram pela Condição DM, à direita. Os mesmos quatro participantes que mostraram porcentagens altas de acertos nos Testes Parciais realizados nos ciclos apresentaram escores altos no Pós-Teste da última condição realizada, independente da ordem de exposição às condições. Os resultados suge- 
rem efeitos mais sistemáticos após a Condição DM (especialmente quando conduzida como Condição 1) do que DC, sugerindo que o treino com menor número de letras em comum entre as palavras foi mais efetivo em gerar leitura recombinativa (assim como maior rapidez na aquisição das discriminações durante a fase de ensino). Enquanto os dois participantes que começaram pela Condição DC apresentaram 100\% de acertos apenas no Pós-teste da segunda condição (DM), aqueles que iniciaram pela Condição DM mostraram escores próximos de $100 \%$ desde a primeira condição (DM). Para os demais participantes os escores foram próximos de zero, replicando os resultados dos Testes Parciais.

Para os participantes que apresentaram desenvolvimento de repertórios recombinativos, os resultados não replicam os de estudos anteriores que manipularam a similaridade entre estímulos para avaliar o controle discriminativo pelos diferentes elementos dos estímulos (Allen \& Fuqua, 1985; Birnie-Selwyn \& Guerin, 1997) e encontraram melhores desempenhos nos testes (mas não nos treinos) após o treino com Diferença Crítica. No entanto, Albuquerque (2001) e Domeniconi, Huziwara e de Rose (2007) apresentaram evidências semelhantes às obtidas no presente experimento: variabilidade entre participantes e melhor desempenho em testes para alguns participantes na Condição DM. Essas controvérsias encontradas na literatura e a variabilidade individual observadas nos estudos requerem investigações adicionais sobre o desenvolvimento de repertório recombinativo e sugerem que o efeito da semelhança entre os estímulos pode depender de outros fatores.

O efeito que se mostrou sistemático no presente experimento foi o da quantidade de palavras ensinadas sobre a emergência de leitura recombinativa (evidenciado pelo progresso ao longo dos ciclos e pela redução na quantidade de tentativas). Esses resultados estão de acordo com os de estudos anteriores que utilizaram delineamentos semelhantes ao do presente experimento (Albuquerque, 2001; Hanna et al., 2008; Quinteiro, 2003) e com os de estudos que empregaram palavras da língua portuguesa (de Rose et al., 1996; Hübner-D'Oliveira \& Matos, 1993; Hübner, Matos, \& Serra, 2002; Hübner, Gomes, \& Mcllvane, 2009; Matos et. al., 1997; 1999).

Os resultados sugerem que a quantidade de palavras ensinadas (que representa oportunidade de experiência com variação nas recombinações entre elementos textuais) é mais importante para a emergência de leitura recombinativa do que o grau de similaridade entre os estímulos de treino. A importância da variação, sugerida por este e outros estudos prévios, encontrou apoio em um estudo conduzido com o Sistema Linguístico em Miniatura que, empregando as mesmas quatro sílabas apresentadas neste estudo, controlou o número de palavras (duas ou 12) e a quantidade de treino (Hanna et al., submetido) e mostrou escores muito mais elevados na condição com maior diversidade palavras (o que significa mais recombinações das mesmas silabas ao longo do treino). 

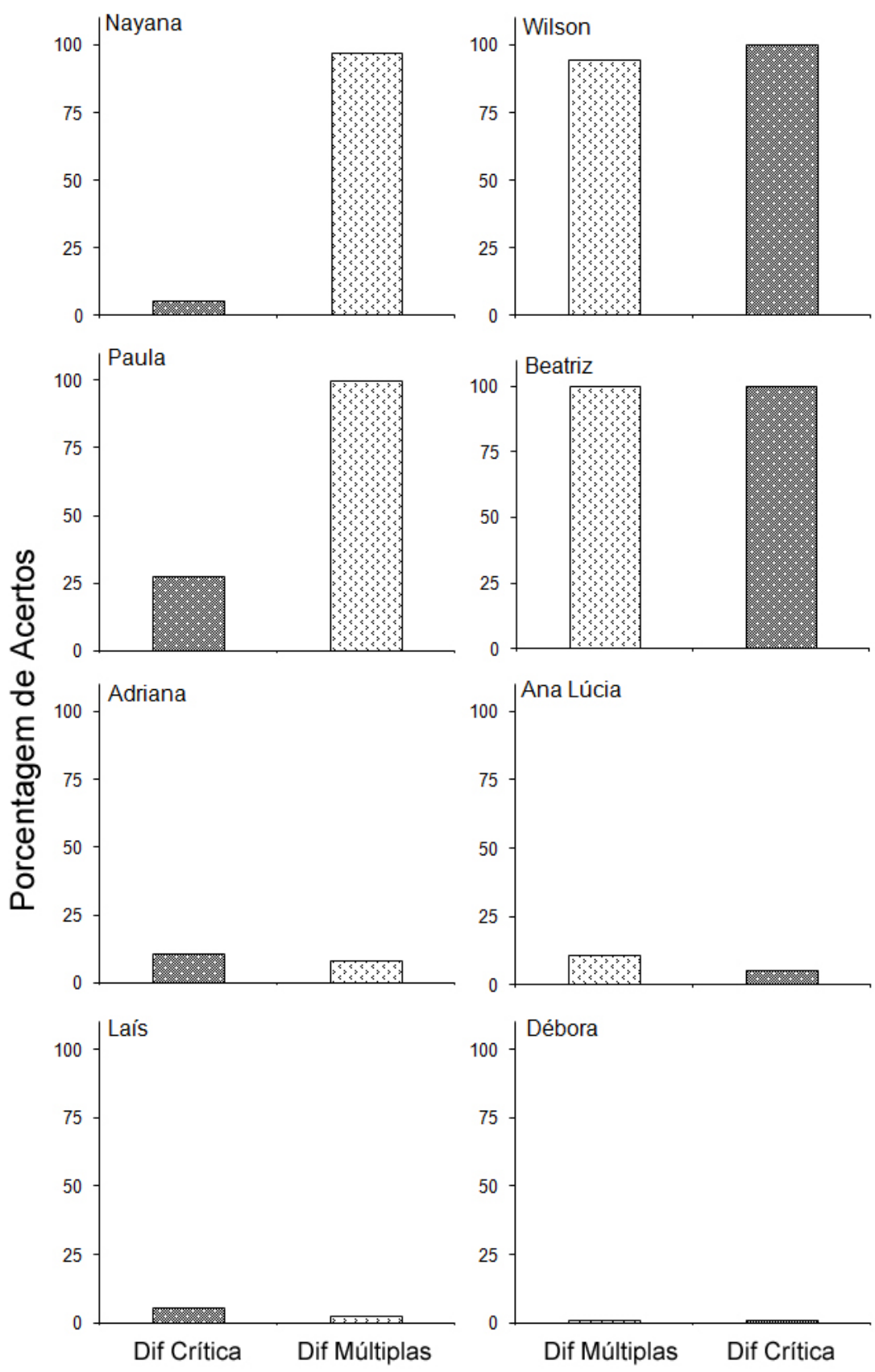

Condições Experimentais

Figura 4. Porcentagem de acertos no pós-teste de leitura oral da Condição Diferença Crítica (barras com fundo cinza) e da Condição Diferenças Múltiplas (barras com fundo branco) para cada participante do Experimento 1. 
O desenvolvimento de controle elementar (abstração) e da relação entre elementos sonoros e textuais é fundamental para a leitura recombinativa, e os resultados deste experimento mostram que o ensino de palavras inteiras pode gerar o controle elementar, como sugerido por Skinner (1957). Contudo, como apontado por Sidman (1994),"o ensino de palavras inteiras deixa ao acaso o reconhecimento, pela criança, das correspondências entre elementos sonoros e textuais ${ }^{\prime \prime 4}(p .78)$. O Experimento 2 explorou o papel da extensão de elementos textuais e sonoros diretamente ensinados na emergência de leitura recombinativa de pseudo-palavras .

\section{Experimento 2}

A influência do ensino direto de unidades menores que a palavra na leitura recombinativa foi demonstrada em estudos anteriores. $O$ ensino de letras ou sílabas foi mais eficiente em gerar transferência de leitura para palavras novas (Bishop, 1964; Silberman, 1964; Jefrey \& Samuels, 1967).

Serejo, Hanna, de Souza e de Rose (2007), utilizando procedimento de pareamento ao modelo, observou que o ensino da unidade de recombinação (sílaba) facilitou a leitura recombinativa, proporcionando maior porcentagem de acertos nos testes de nomeação. De Souza et al. (2009b) ensinaram discriminações condicionais entre sílabas impressas e ditadas sobrepostas ao ensino das mesmas relações com palavras inteiras e observaram escores elevados de leitura recombinativa com todos os 20 participantes do estudo e menor variabilidade interindividual do que quando apenas palavras eram ensinadas. Muller et al. (2000) ensinaram relações auditivo-visuais entre palavras monossilábicas, mas manipularam sistematicamente os fragmentos (letra inicial e terminação) das palavras, mostrando que quando todos os componentes são ensinados (ainda que "embutidos" nas palavras), a leitura recombinativa emerge de maneira sistemática e previsível.

No estudo de Bishop (1964) as palavras eram formadas a partir de letras árabes. A autora produziu dois conjuntos de 8 palavras diferentes, um empregado para ensinar e outro para testar a transferência de leitura. Sessenta participantes foram divididos em três grupos: um grupo treinado com todas as letras, um grupo treinado com palavras e um grupo controle que realizou um treino não relacionado ao desempenho requerido na tarefa experimental. Nos testes de transferência ou de recombinação, as palavras novas eram formadas pelas mesmas letras componentes dos estímulos de treino, fossem eles palavras ou letras. Os resultados mostraram que tanto os participantes do grupo treinado com letras quanto os do grupo treinado com palavras foram capazes de ler as palavras novas, enquanto o grupo controle fracassou na tarefa. No entanto, o desempenho do grupo

\footnotetext{
4 "a whole-word method of teaching reading leaves to chance a pupil's recognition of the correspondences between sounds and textual elements".
} 
treinado com letras foi muito superior ao do grupo treinado com palavras, com uma média menor de tentativas para alcançar o critério de aprendizagem. Além disso, entre os participantes que não leram palavras novas, apenas um havia aprendido letras, enquanto sete haviam aprendido palavras.

Como sugeriu Sidman (1994), apesar do ensino com palavras inteiras ser menos eficaz (mas não completamente ineficaz) para estabelecer leitura recombinativa, esta estratégia pode assegurar que um aluno adquira rapidamente um repertório inicial de compreensão de leitura "que pode ser usado como base para o ensino de correspondências entre os componentes de sons (as palavras faladas) e os componentes das palavras impressas que o aluno compreende" (p. 79).

Com base nessas considerações, parece que uma combinação de variáveis que poderia maximizar a leitura recombinativa seria uma que permitisse estabelecer diretamente o controle pelas "menores unidades" que compõem os estímulos textuais para os quais se espera que o aluno apresente leitura recombinativa plena, com compreensão.

Com base nessa sugestão e considerando as vantagens do Sistema Linguístico em Miniatura, desenvolvido em estudos prévios e empregado no Experimento 1) no controle de variáveis da experiência pré-experimental dos participantes, o presente experimento teve por objetivo investigar o efeito da extensão das unidades (sonoras e textuais) ensinadas sobre a emergência de leitura recombinativa de palavras inteiras.

\section{Método}

\section{Participantes}

Participaram do estudo oito estudantes com idade entre 19 e 22 anos da Universidade de Brasília selecionados a partir de avisos em sala de aula. Os critérios de seleção e recrutamento foram os mesmos utilizados no Experimento 1.O tempo de participação no experimento foi convertido em pontos-extra para os estudantes aprovados na disciplina (máximo de 5 pontos em 100). Os alunos interessados assinaram um Termo de Consentimento Livre e Esclarecido, preencheram um formulário com informações pessoais e sobre o domínio de língua estrangeira.

\section{Situação e equipamentos}

Foram iguais aos do Experimento 1.

\section{Estímulos}

Foram utilizados os mesmos estímulos da Condição Diferenças Múltiplas do Experimento 1 durante o ensino das relações entre palavras faladas e impressas. A Tabela 5 apresenta, em alfabeto romano, as palavras correspondentes às palavras impressas com o pseudoalfabeto (conforme Figura 1) utilizadas nas fases de ensino e testes. 
Tabela 5. Palavras ensinadas e testadas em cada ciclo do Experimento 2.

\begin{tabular}{cccclll}
\hline Ciclo & \multicolumn{2}{c}{ Palavras Ensinadas } & \multicolumn{4}{c}{ Palavras Testadas } \\
\hline 1 & nibo & fale & lofi & Nibe & falo & bena \\
2 & bofa & leni & nale & Bofi & falo & bena \\
3 & lebo & fani & nofa & Leba & falo & bena \\
4 & boni & lefa & lefi & Bona & falo & bena \\
5 & fabo & nile & nilo & Fabe & falo & bena \\
6 & bole & nifa & febi & Lano & falo & bena \\
\hline
\end{tabular}

\section{Procedimento}

A sequência geral do procedimento foi Pré-Treino, Ensino de relações entre unidades sonoras e as textuais correspondentes (letras ou sílabas), Teste Inicial de leitura oral de palavras, Ensino e Testes Parciais com palavras (Treino AC/CD e Testes C'D e A'C') e Teste Final de leitura oral de palavras.

Pré-Treino. Igual ao realizado no Experimento 1.

Emparelhamento Auditivo-Visual com Letras ou Sílabas. Metade dos participantes aprendeu a selecionar sílabas escritas com o pseudoalfabeto correspondentes às sílabas ditadas. A outra metade aprendeu a selecionar as letras escritas com o pseudoalfabeto correspondentes aos nomes das letras ditados.

Os treinos de letras e sílabas consistiram de tentativas de pareamento e nomeação programadas de forma similar à do Treino AC/CD do Experimento 1. Cada treino ensinava duas letras ou duas sílabas na ordem: N/I, $\mathrm{B} / \mathrm{O}, \mathrm{F} / \mathrm{A}$ e L/E para letras, e NI/BO e FA/LE para sílabas. Os quatro treinos de letras eram realizados em duas sessões e os treinos de sílabas ocorriam em uma única sessão. Os estímulos incorretos de cada tentativa eram escolhidos entre as oito letras (para o treino com letras) ou entre as quatro sílabas (para o treino com sílabas). Blocos de tentativas de treino eram realizados até o critério de $100 \%$ de acertos.

Teste Inicial de Leitura Oral. Após o treino com sílabas ou letras realizava-se um teste de nomeação de 26 palavras impressas, 12 palavras de treino e 14 de teste mostradas na Tabela 5.

Ensino e Testes Parciais com palavras (Treino AC/CD e Testes C'D e $\left.\mathbf{A}^{\prime} \mathbf{C}^{\prime}\right)$. Eram realizados seis ciclos de treino e testes semelhantes aos descritos no Experimento 1 (Treino AC/CD e Testes $C^{\prime} D$ e $A^{\prime} C^{\prime}$ ), com pseudopalavras. A cada ciclo, treinavam-se duas palavras e testavam-se quatro, sendo que duas palavras de teste eram iguais em todos os ciclos (FALÓ e BENÁ).

Teste Final de Leitura Oral. Após os seis ciclos, era realizado novamente o teste de nomeação com as mesmas 26 palavras do Teste inicial. 


\section{Resultados e Discussão}

O índice de acordo entre experimentador/observador foi de 95,8\% de um total de 1574 tentativas.

O procedimento foi concluído em sete sessões para os participantes que aprenderam sílabas e em oito para os que aprenderam letras.

No treino inicial de letras ou sílabas todos os participantes apresentaram altos percentuais de acerto, com poucos erros, e alcançaram o critério de aprendizagem no número de sessões inicialmente programadas. Todavia, nenhum participante terminou o treino com o mínimo de tentativas programadas (236 para o Grupo Letras e 86 para o Grupo Sílabas).

A Tabela 6 mostra o total de tentativas até o critério de aprendizagem, as tentativas além das programadas e o número de erros de cada participante. $O$ número máximo de erros foi 5 , o que gerou um aumento de no máximo 12 tentativas para os participantes que aprenderam letras e 46 tentativas para os que aprenderam sílabas. $\mathrm{O}$ total de tentativas do treino de letras foi maior do que no treino com sílabas devido ao número mínimo de tentativas programadas para cada treino. Sendo assim, o treino com letras gerou maior exposição aos estímulos (letras) do que o treino com sílabas.

Tabela 6. Número de tentativas realizadas, Tentativas excedentes e Número de erros no Treino AC/CD com letras ou sílabas do Experimento 2.

\begin{tabular}{ccccc}
\hline \multirow{2}{*}{ Treino } & Participantes & Tentativas & Tent. Excedente & Total erros \\
\hline \multirow{2}{*}{ Letras } & Denise & 247 & 11 & 5 \\
& Marina & 248 & 12 & 3 \\
& Andréa & 239 & 3 & 3 \\
\multirow{5}{*}{ Sílabas } & João & 244 & 8 & 3 \\
& Joana & 98 & 12 & 5 \\
& Roberta & 128 & 42 & 5 \\
& Fabiana & 132 & 46 & 4 \\
& Anderson & 91 & 5 & 2 \\
\hline
\end{tabular}

As porcentagens individuais de acertos nos testes de leitura oral de palavras são apresentadas na Figura 5. A primeira barra de cada gráfico apresenta os resultados do Teste inicial (I) com 26 palavras, realizado logo após o treino com letras (gráficos à esquerda) ou com sílabas (gráficos à direita), mas antes do emparelhamento com palavras. As seis barras subsequentes representam os resultados dos testes $C^{\prime} D$ de cada ciclo (1 a 6) e a última barra mostra os resultados do teste $C^{\prime} D$ final $(F)$. Devido à elevada 
ocorrência de palavras corretas quanto à correspondência ponto a ponto entre grafemas e fonemas e sua sequência, mas com pronúncia incorreta quanto à tonicidade (por exemplo, em vez de NIBÓ, pronunciar a palavra como paroxítona - NíBO), foi calculada a porcentagem dessas emissões. Os resultados são mostrados na porção cinza acima das barras de acertos (porção hachurada das barras), que exclui erros de pronúncia.

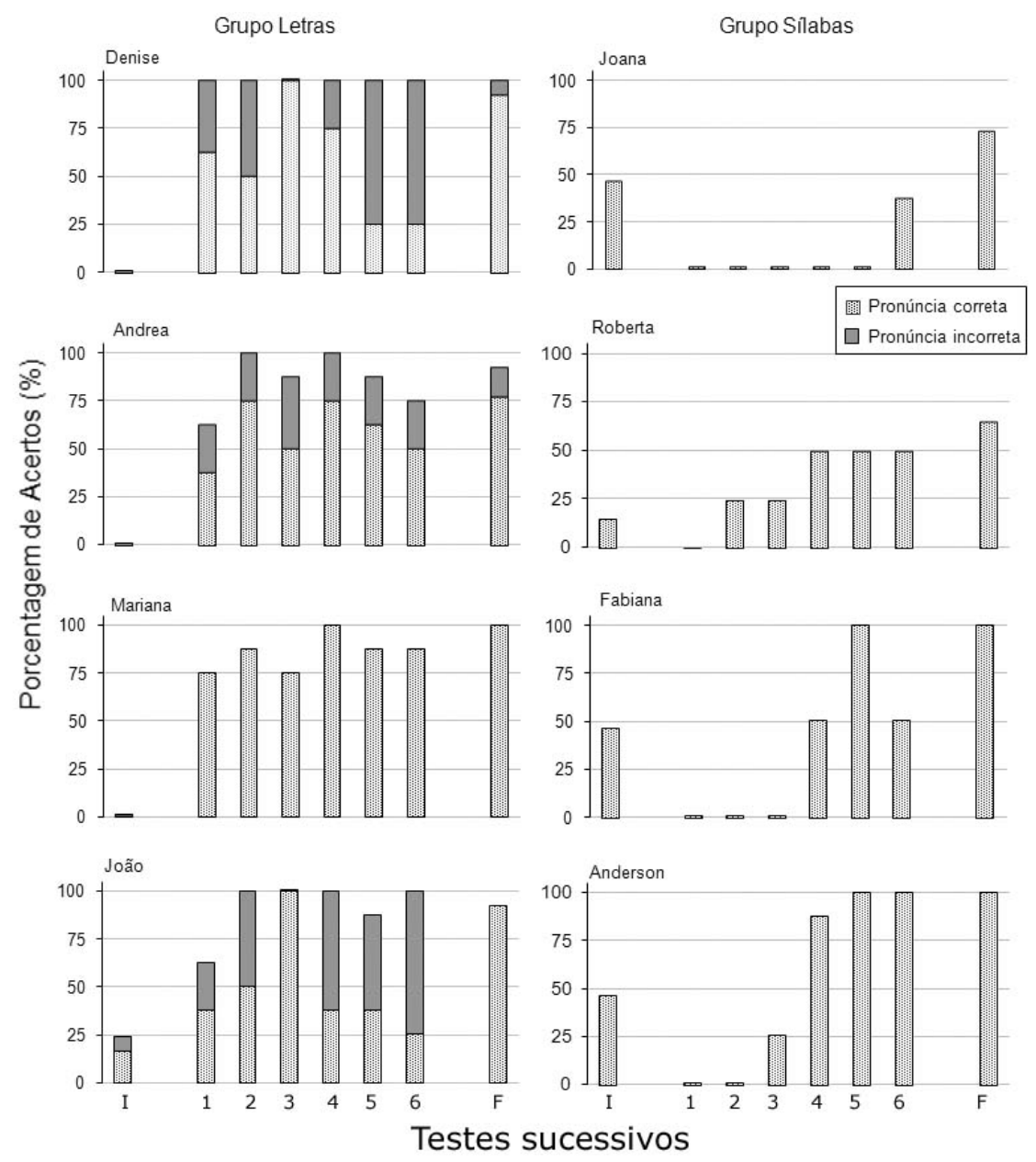

Figura 5. Porcentagem de acertos com pronúncia correta (barra hachurada) e com pronúncia incorreta (barra cinza, erro de tonicidade) na nomeação de palavras impressas no Teste Inicial (I), no teste de cada um dos seis ciclos experimentais e no Teste Final (F), para cada participante do Experimento 2. 
No Teste Inicial os participantes que haviam aprendido os nomes das letras não leram palavras (exceto João, que apresentou $25 \%$ de acertos). Após a aprendizagem de sílabas, três dos quatro participantes leram aproximadamente $50 \%$ das 12 palavras e a quarta (Roberta) leu $(15,4 \%)$. Todas as palavras lidas por esses participantes eram formadas pelas sílabas que haviam sido ensinadas (os dados do Teste Inicial também podem ser analisados na Figura 6, que apresenta os escores de leitura de palavras nos testes Inicial e Final, separados por tipo de palavra: de treino - com as sílabas treinadas, e de recombinação - com recombinação intra-silábica). Os participantes que aprenderam as letras, em geral, soletraram as palavras escritas, o que foi analisado como erro. Isso parece indicar que a utilização de letras como unidade de treino impossibilita a compreensão da palavra inteira, sendo imprescindível a exposição às palavras para que se desenvolva o repertório de combinação ou junção das letras aprendidas na emissão de palavras inteiras. Esse resultado é especialmente interessante, considerando que os estudantes universitários têm uma extensa experiência em combinar letras e formar palavras na língua portuguesa e os fonemas correlacionados com as letras do pseudoalfabeto e as regras de combinação eram os mesmos de sua língua materna. Esses resultados confirmam descobertas prévias de que a utilização de um Sistema Linguístico em Miniatura pode fornecer dados relevantes para o conhecimento sobre o desenvolvimento linguístico de seres humanos, mesmo quando a investigação é conduzida com participantes com longa experiência no uso de linguagem (Esper, 1925; Foss, 1968; Hanna et al., 2008; Wetherby, 1978).

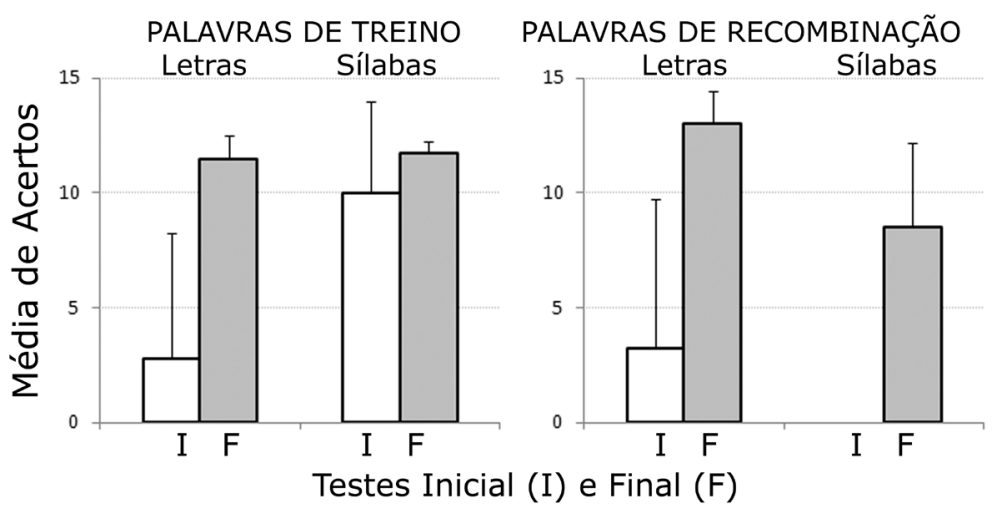

Figura 6. Número de acertos (média) nos Testes Inicial e Final de Nomeação de palavras impressas por tipo de palavra (de treino e de generalização) e por condição de ensino (Letras, Sílabas) do Experimento 2. Linhas verticais representam um desvio-padrão da média. 
Ao longo dos ciclos de ensino das palavras os participantes do Grupo Letras apresentaram elevadas porcentagens na leitura oral de palavras nos Testes C'D em todos os ciclos, especialmente se erros de pronúncia forem considerados como acertos; os participantes do Grupo Sílabas não leram palavras ou apresentaram escores baixos nos ciclos iniciais, mas apresentaram aumento gradual nos escores de leitura ao longo dos ciclos; seus escores finais, no entanto, permaneceram menores que os do Grupo Letras.

No Teste Final com as 12 palavras de treino e 14 de recombinação, todos os participantes de ambos os grupos leram a maioria das palavras. Os estudantes que aprenderam letras antes das pseudopalavras obtiveram percentuais de acertos entre $90 \%$ (dois participantes) e $100 \%$ (dois participantes); dos que aprenderam sílabas, dois acertaram $100 \%$ e os outros dois apresentaram $62,5 \%$ e $75 \%$ de acertos.

De modo geral, os escores em leitura recombinativa após a aprendizagem de letras foram mais elevados e consistentes quando se considera os resultados de todos os testes do grupo e se desconsidera os erros de pronúncia. Porém, esses erros foram muito frequentes (chegando a $75 \%$ para alguns participantes), ao passo que nenhum erro deste tipo foi observado para os participantes que aprenderam as sílabas. Deve ser considerado que os resultados talvez fossem diferentes se os sons isolados (e não o nome das letras) tivessem sido ensinados, mas esta é uma questão que requer verificação experimental. Tendo em vista que as sílabas constituem uma unidade natural na língua portuguesa, a aprendizagem de sílabas como unidade parece ter gerado imediatamente a combinação em palavras de duas sílabas, o que não ocorreu quando os participantes aprenderam os nomes das letras. Esse resultado apoia a noção de que, enquanto em línguas menos transparentes a leitura recombinativa pode se beneficiar do ensino de unidades intra-silábicas (Mueller et al., 2000), em línguas como o português, com maior regularidade nas correspondências somtexto, unidades silábicas podem ter um papel importante na geração de leitura recombinativa. Nessas línguas é possível, a partir do controle pelas unidades silábicas ensinadas, a produção vocal de palavras inteiras e com significado, isto é, palavras a que o leitor pode reagir como ouvinte (Greer \& Ross, 2007; Skinner, 1957), ou que entram em classes de equivalência com outros componentes da classe (Sidman, 1994).

O Teste de Recombinação $A^{\prime} C^{\prime}$ mediu a recombinação em leitura receptivo-auditiva, cujos resultados (média de grupo) encontram-se na Figura 7.0 percentual médio de acertos foi alto em todos os ciclos, sempre acima de $75 \%$, com desempenho um pouco mais baixo para os participantes que aprenderam as Sílabas, nos três primeiros ciclos. Os desvios-padrões de ambos os grupos foram baixos, mas o do Grupo Sílabas foi um pouco maior que do Grupo Letras. Esses dados estão de acordo com os de outros estudos que compararam leitura oral e leitura por seleção (eg., de Rose et al., 1996; Hanna et al., 2008) e sugerem que no desenvolvimento de con- 
trole textual o comportamento de ouvinte precede o de falante, isto é, o indivíduo aprende a reconhecer um texto que corresponde a um estímulo falado antes que seja capaz de emitir a resposta vocal com correspondência ponto a ponto com o texto (Greer \& Ross, 2007; Skinner, 1957).

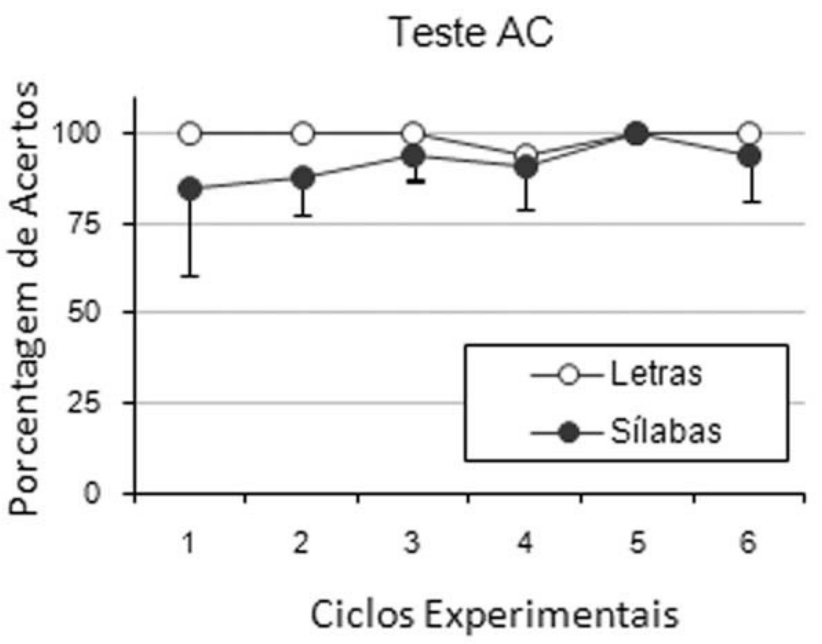

Figura 7. Porcentagem de acertos (média) nos Testes de Recombinação AC (seleção de palavra impressa correspondente à palavra falada) em cada ciclo experimental para as Condições Letras e Sílabas. Linhas verticais representam um desvio-padrão da média.

Por fim, foram analisados os tipos de erros cometidos nos testes Inicial e Final, a partir de categorias de respostas. No Teste Inicial os erros do Grupo Letras consistiram, majoritariamente, em soletrar (em vez de dizer a palavra) e em pronunciar as palavras com acentuação da primeira sílaba. $O$ Grupo Sílabas apresentou um padrão diferente de erros: dizer uma palavra ensinada, dizer apenas uma sílaba e dizer "não sei". No teste de nomeação Final, o número de erros foi $76 \%$ menor do que no teste de nomeação Inicial, mostrando o progresso dos participantes na leitura recombinativa e os dois tipos de erros mais frequentes foram "errar uma letra" e errar a "pronúncia" para os Grupos Sílabas e Letras, respectivamente.

Os erros são indicadores de que o Treino Letras ou Sílabas que precedeu o Teste Inicial de leitura oral foi eficiente em ensinar o que se propunha: 1) a maioria dos participantes do Grupo Letras soletrou corretamente as letras de todas as palavras apresentadas; e 2) muitos participantes do Grupo Sílabas só pronunciaram as sílabas treinadas que se encontravam recombinadas nas palavras compostas por estas sílabas, mostrando que aprenderam as relações ensinadas. Os erros foram superados quando pala- 
vras inteiras foram ensinadas. O que cabe considerar é a diferença de efeito dessa aprendizagem prévia sobre a leitura recombinativa.

\section{Discussão Geral}

O objeto de interesse nos dois experimentos incluídos neste relato foi a leitura combinatória ou recombinativa e o papel de variáveis dos procedimentos de ensino na geração desse repertório.

O desenvolvimento de abstração de unidades de controle de estímulos por relações som-texto é o processo básico no desenvolvimento de leitura recombinativa. Na leitura recombinativa, o responder apropriado diante de texto novo ocorre a partir do controle que fragmentos do texto exerce sobre cada fragmento de resposta, controle este aprendido (abstraído) a partir da experiência anterior com outros textos.

No presente estudo o Sistema Linguístico em Miniatura inventado mostrou-se útil para investigar, com universitários, os efeitos de dois tipos de variáveis sobre a leitura recombinativa avaliada em termos de leitura oral ou comportamento textual e de leitura por seleção (reconhecimento de palavras). Em ambos os experimentos, foram manipuladas variáveis no ensino da linha de base inicial de discriminações e relações condicionais som-texto, a partir da qual a leitura recombinativa foi medida. A pergunta central era se as variáveis manipuladas ou valores dessas variáveis, no ensino das relações básicas, favoreceriam o desenvolvimento de abstração.

O primeiro experimento perguntou sobre o papel da similaridade entre palavras na discriminação entre os estímulos de comparação, que eram palavras impressas, na fase de ensino e as implicações para o desenvolvimento de leitura recombinativa. Um dos princípios da discriminação é que quanto maior a diferença entre dois estímulos, mais fácil a discriminação entre eles. No caso de estímulos textuais, provavelmente é mais fácil discriminar entre as palavras PIPA e FOGO, do que entre as palavras BOTA e BOLA. As duas condições experimentais - Diferenças Múltiplas e Diferença Crítica, do Experimento 1 simularam essas características: no primeiro caso as palavras eram diferentes: tinham apenas um elemento em comum; no segundo, as palavras eram similares: tinham três elementos em comum. Os resultados replicaram os de estudos prévios no que concerne à aprendizagem discriminativa: o critério de aprendizagem foi atingido mais rapidamente e com menor número de erros na Condição Diferenças Múltiplas. Nos testes de leitura recombinativa, tanto de leitura oral quanto de leitura por seleção, ocorreu variabilidade entre os participantes: metade mostrou desempenhos emergentes e metade, não; em um caso como no outro, não foi possível distinguir o papel das duas condições de treino. Desse ponto de vista, os resultados dos participantes que apresentaram leitura de palavras novas discrepam dos de alguns outros estudos, que mostraram piores desempenhos nos testes após a discriminação de estímulos com 
diferenças múltiplas (Allen \& Fuqua, 1985; Birnie-Selwyn \& Guerin, 1997), mas concordam com os de outros (Albuquerque, 2001; Domeniconi et al., 2007) que mostraram controle elementar mesmo depois de treino discriminativo com diferenças múltiplas (há que se considerar com cautela as diferenças nos desempenhos testados nos diferentes estudos, assim como as diferenças entre o que é requerido de um participante nos treinos e nos testes). No contexto do presente estudo, os resultados positivos nos testes sugerem que se pode chegar à abstração por ambas as vias; por outro lado, os dados negativos sugerem que para outros participantes a aprendizagem de discriminação entre os estímulos originais (assegurada pelo rigoroso critério para o encerramento da fase de ensino) foi insuficiente para estabelecer abstração e, consequentemente, leitura recombinativa.

O fato de que os participantes que apresentaram leitura recombinativa passaram a fazê-lo, em média, depois do treino de seis palavras ( 3 ciclos treinos-testes - Figura 3) sugere que a quantidade de treino tem efeito sobre a emergência do controle elementar, imprescindível para a leitura recombinativa; à medida que os participantes se deparavam com novas palavras de treino, deparavam-se também com as mesmas unidades ou elementos de som e texto em posições diferentes, isto é, quanto mais palavras ensinadas, maior a experiência com a recombinação nos estímulos (que ocasionava recombinação nas respostas), proporcionada pelo procedimento. Esta alteração constante da posição de unidades som-texto nos estímulos de treino pode também contribuir para impedir que um controle de estímulo seletivo se estabeleça sobre o desempenho do participante (NIBO e BONI eram duas palavras de treino que exigiam, no mínimo, um controle pelas sílabas para que o participante pudesse acertar e eram formadas exatamente pelas mesmas letras, em posições alteradas). É possível que os participantes que não abstraíram viessem a fazê-lo se continuassem sendo expostos a novas recombinações. Um procedimento que fosse ampliando o conjunto de palavras ensinadas (e controlasse a quantidade de recombinações) até que todos os participantes apresentassem repertório recombinativo informaria sobre uma faixa de variabilidade interindividual na quantidade de treino necessária para atingir o critério e permitiria estimativas sobre valores dessa variável com probabilidade de gerar recombinação. Esta alternativa esbarra no limite de combinações possíveis com o mini-sistema e uma forma de superar o limite seria introduzir um segundo conjunto de estímulos, diferente do primeiro, a partir dos quais seriam geradas as palavras estímulo, o que possibilitaria, adicionalmente, a avaliação de efeitos de learning set.

O segundo experimento investigou o efeito da extensão dos elementos textuais ensinados. Relações elementares foram ensinadas antes do ensino de relações som-texto de pseudopalavras inteiras. A estratégia de avaliar a leitura de palavras após a aprendizagem das relações elementares (no Teste Inicial) permitiu aferir direta e isoladamente o efeito dessa 
aprendizagem sobre a leitura oral de palavras. Os resultados mostraram que o domínio de relações silábicas permite o controle imediato por essas unidades inseridas em palavras. Portanto, do ponto de vista do repertório instalado, pode-se dizer que os indivíduos foram capazes de combinar suas respostas sob controle da combinação de sílabas em palavras (leitura combinatória) e o procedimento permitiu aferir as primeiras instâncias de ocorrência desse comportamento. Os termos combinação e recombinação são geralmente tomados como sinônimos na análise de repertórios novos derivados de relações previamente aprendidas, mas podem resultar de processos diferentes. $O$ termo recombinação deveria ser reservado para designar ocorrências em que unidades elementares foram aprendidas no contexto de estímulos compostos e passam a exercer controle sobre o comportamento no contexto de outros estímulos compostos, que incluem a(s) unidade(s) abstraída(s).

O fato de que os participantes que aprenderam apenas os nomes das letras não conseguiam ler palavras inteiras, apenas soletrar os elementos, mesmo sendo universitários, é uma informação original - só possibilitada pelo uso do MSL - e que tem implicações consideráveis para a compreensão do comportamento do leitor como ouvinte de si mesmo, e do papel da comunidade verbal na origem do repertório de falante/leitor (possivelmente em comportamentos operantes elementares como o comportamento ecoico ou a imitação vocal): o fato de que os participantes mudaram o padrão de responder no Teste Final, depois de terem ouvido apenas 12 palavras ditadas na fase de ensino, é evidência do papel crítico dos modelos verbais na origem da fala (seja com função ecoica, textual ou outra).

Os procedimentos para ensinar relações entre elementos som-texto têm envolvido o ensino direto (como neste experimento; Barros, 2007; Maués, 2007), indireto, pela manipulação e, sobretudo, pela superposição sistemática de estímulos elementares nos estímulos compostos (eg., Matos et al. 2006; Mueller et al., 2000) ou combinado (eg., de Souza et al., 2009b). Do ponto de vista da aplicação das descobertas sobre controle elementar na aquisição de leitura ao desenvolvimento de tecnologias de ensino, as evidências científicas acumuladas sugerem que uma estratégia eficaz deveria incluir o ensino combinado, simultâneo ou alternado, de relações elementares e de relações entre estímulos compostos. Uma das possibilidades mais promissoras consiste em superpor sistematicamente elementos em diferentes estímulos compostos (palavras, no presente caso), de preferência com um planejamento controlado por matrizes de ensino (cf. Goldstein, 1983; Mueller et al., 2000).

Do ponto de vista da investigação de processos básicos, a literatura psicológica apresenta muita informação sólida sobre as condições que geram abstração a partir das discriminações de unidades mais amplas, mas ainda estão por ser determinadas as condições necessárias e suficientes para gerar abstração e garantir leitura recombinativa para todos - e não 
somente para alguns participantes, de modo que se possa predizer e controlar esse comportamento e fornecer subsídios mais seguros para o desenvolvimento de tecnologias de ensino.

\title{
Recombinative reading of pseudo-words printed with a pseudo-alphabet: similarity between words and teaching unit size
}

\begin{abstract}
Discriminative control by textual elements is a requisite for reading new words (recombinative reading). This study used pseudowords printed with pseudo-alphabet to evaluate the effects of the similarity between words and the size of teaching units on the development of recombinative reading. In Exp. 1 , undergraduate students learned conditional relations between spoken and printed pseudowords which differed from incorrect words in $25 \%$ and $75 \%$ of the elements. In Exp. 2, undergraduate students learned to relate spoken letters or syllables to the corresponding printed units and afterwards they learned the conditional relations with pseudowords. The acquisition of discriminations was faster during the Condition 75\%; recombinative reading was related to the amount of trained words (Exp. 1). Reading accuracy was higher after learning syllables, but more recombinative reading occurred after learning letters (Exp. 2). The teaching that combines dissimilar words and units smaller than words may accelerate recombinative reading.
\end{abstract}

Keywords: Reading. Recombinative reading. Pseudo-alphabet. Stimulus similarity. Extension of textual unit Undergraduate students.

\section{Lecture Recombinative de pseudomots imprimés avec le pseudo-alphabet: similitude entre les mots et l'extension de I'unité d'enseignement}

Résumé: La discrimination des textuels est essentielle pour la lecture denouveauxmots (lecture recombinant).Cetteétudea employé des pseudomots dictés et imprimés avec un pseudo-alphabet pour étudier les effets de la similitude entre les mots et de l'extension de l'unité textuelle enseignée sur le développement de la lecture recombinant.Dans l'Exp. 1, universitaires ont appris des relations conditionnelles entre pseudomots dictés et imprimés qui ont différé des mots incorrects dans $25 \%$ et 75\% des éléments. Dans l'Exp. 2, d'autres universitaires ont appris a relation des lettres ou des syllabes dictées à correspondantes imprimées et après ils ont appris les relations avec les pseudo-mots. L'acquisition des discriminations était plus rapide à Condition Différence $75 \%$; la lecture recombinante a été liée à la quantité de mots enseignés (Exp 
1). La lecture a montré plus d'exactitude juste après l'apprentissage des relations avec des syllabes, mais la lecture recombinante a été favorisée par l'apprentissage des lettres. Combiner l'enseignement des mots plus différents et des unités d'enseignement petites peut accélérer la lecture recombinante.

Mots clés: Lecture. Lecture recombinative. Pseudo-alphabet. Similitude de stimulus. Extension d'unité textuelle. Étudiants universitaires.

\section{La lectura con recombinación de pseudopalabras impresas en pseudo-alfabeto: semejanza entre las palabras y el tamaño de la unidad enseñada}

Resumen: El control discriminatorio por elementos textuales es necesario para que se lea nuevas palabras (lectura con recombinación). Ese estudio utilizó pseudopalabras impresas en pseudo-alfabeto para investigar los efectos de la semejanza entre palabras y del tamaño de la unidad textual enseñada sobre el desarrollo de la lectura con recombinación. En el Exp. 1 universitarios aprendieron relaciones condicionales entre pseudopalabras dictadas e impresas que se diferenciaban de las palabras incorrectas en $25 \%$ y $75 \%$ de los elementos. En el Exp. 2, otros estudiantes aprendieron a relacionar letras o sílabas dictadas con sus correspondientes unidades impresas y después aprendieron las relaciones involucrando las pseudopalabras. Adquisición de las discriminaciones fue más rápida en la Condición Diferencia 75\%; la lectura con recombinación estuvo relacionada con la cantidad de palabras entrenadas (Exp.1).Exp. 2 demostró mayor precisión de lectura después de la aprendizaje de silabas, pero la lectura con recombinación fue favorecida por la aprendizaje de letras. Conciliar la enseñanza de palabras disímiles y de unidades más pequeñas que palabras puede acelerarse la lectura con recombinación.

Palabras claves: Lectura. Lectura con recombinación. Pseudo-alfabeto. Semejanza del estímulo. Extensión de la unidad textual. Estudiantes universitarios

\section{Referências}

Adams, M. J. (1994). Beginning to read: Thinking and learning about print. Cambridge, MA: MIT Press.

Albuquerque, A. R. (2001). Controle comportamental por símbolos compostos: manipulação da similaridade entre estímulos discriminativos e do número de recombinações treinadas. Tese de Doutorado, Universidade de Brasília, Brasília, DF. 
Albuquerque, A. R., \& Hanna, E. S. (2001). Efeito do grau de similaridade entre palavras compostas por um pseudo-alfabeto em desempenhos treinados e generalizados de leitura. Resumos de Comunicações Científicas da XXXI Reunião Anual de Psicologia, Sociedade Brasileira de Psicologia (Vol. 1, p. 30). Rio de Janeiro.

Alessi, G. (1987). Generative strategies and teaching generalization. The Analysis of Verbal Behavior, 5, 15-27.

Allen, K. D., \& Fuqua, R. W. (1985). Eliminating selective stimulus control: A comparison of two procedures for teaching mentally retarded children to respond to compound stimuli. Journal of Experimental Child Psychology, 39, 55-71.

Barros, S. N. (2007). Ensino de discriminações de sílabas e a emergência da leitura recombinativa em crianças pré-escolares. Dissertação de Mestrado, Universidade Federal do Pará, Belém, PA.

Birnie-Selwyn, B., \& Guerin, B. (1997). Teaching children to spell: Decreasing consonant clusters errors by eliminating selective stimulus control. Journal of Applied Behavior Analysis, 30, 69-91.

Bishop, C. H. (1964). Transfer effects of word and letter training in reading. Journal of Verbal Learning and Verbal Behavior, 3, 215-221.

de Rose, J.C., de Souza, D. G., \&Hanna, E. S. (1996). Teaching reading and spelling: Exclusion and stimulus equivalence. Journal of Applied Behavior Analysis, 29, 451-469.

de Souza, D. G., \& de Rose, J. C. (2006). Desenvolvendo programas individualizados para o ensino de leitura. Acta Comportamentalia, 14(1), 77-98.

de Souza, D. G., de Rose, J. C., \& Domeniconi, C. (2009a). Applying relational operants to reading and spelling. In R. A. Rehfeldt \& Y. Barnes-Holmes (Eds.), Derived relational responding: Applications for learners with autism and other developmental disabilities (pp. 171-207). Oakland, CA: New Harbinger.

de Souza, D. G., de Rose, J. C., Faleiros, T. C., Bortoloti, R., Hanna, E. S., \& Mcllvane, W. J. (2009b). Teaching generative reading via recombination of minimal textual units: A legacy of Verbal Behavior to children in Brazil. International Journal of Psychology and Psychological Therapy, 9(1), 19-44.

de Souza, D. G., de Rose, J. C., Hanna, E. S., Calcagno, S., \& Galvão, O. F. (2004). Análise comportamental da aprendizagem de leitura e escrita e a construção de um currículo suplementar. In M. M. C. Hübner \& M. Marinotti (Orgs.), Análise do comportamento para a educação: contribuições recentes (pp. 177-203). Santo André, SP: ESETec. 
Domeniconi, C., Huziwara, E. M., \& de Rose, J. C. (2007). Equivalência de estímulos em participantes com Síndorme de Down: efeitos da utilização de palavras com diferenças múltiplas ou críticas e análise de controle restrito de estímulos. Revista Brasileira de Análise do Comportamento, 3(1), 47-63.

Dube, W. V. (1991). Computer software for stimulus control research with Macintosh computers. Experimental Analysis of Human Behavior Bulletin, 9(2), 28-30.

Esper, E. A. (1925). A technique for the experimental investigation of associative interference in artificial linguistic material. Language Monographs, 1, 4-6.

Fonseca, M. L. (1997). Diagnóstico de repertórios iniciais de leitura e escrita: uma análise baseada na concepção de relações de equivalência. Dissertação de Mestrado, Programa de Pós-Graduação em Educação Especial, Universidade Federal de São Carlos, São Carlos, SP.

Foss, D. J. (1968). An analysis of learning in a miniature linguistic system. Journal of Experimental Psychology, 76, 450-459.

Goldstein, H. (1983). Training generative repertoires within agent-action-object miniature linguistic systems with children. Journal of Speech and Hearing Research, 26(1), 76-89.

Goldstein, H. (1993). Structuring environmental input to facilitate generalized language learning by children with mental retardation. In A. P. Kaiser \& D. B. Gray (Eds.), Enhancing children's communication: Research foudations for intervention (pp. 317-334). Baltimore: Paul H. Brookes.

Greer, R. D., \& Ross, D. E. (2007). Verbal behavior analysis: Inducing and expanding new verbal capabilities in children with language delays. NewYork: Allyn \& Bacon.

Hanna, E. S., de Souza, D. G., de Rose, J. C. C., \& Fonseca, M. G. (2004). Effects of delayed constructed-response identity matching on spelling of dictated words. Journal of Applied Behavior Analysis, 37, 223-228.

Hanna, E. S., Kohlsdorf, M., Quinteiro, R. S., Fava, V. M.D., de Souza, D. G., \& de Rose, J. C. (2008). Diferenças individuais na aquisição de leitura com um sistema lingüístico em miniatura. Psicologia: Teoria e Pesquisa, 24(1), 45-58.

Hanna, E. S., Kohlsdorf, M., Quinteiro, R. S., Melo, R. M., de Souza, D. G., de Rose, J. C., \& Mcllvane, W. J. (Submetido). Recombinative reading derived from pseudoword instruction in a miniature linguistic system. Journal of the Experimental Analysis of Behavior. 
Hübner, M. M. C, Gomes, R. C., \& Mcllvane, W. (2009). Recombinative generalization in minimal verbal unit-based reading instruction for pre-reading children. Experimental Analysis of Human Behavior Bulletin, 27, 11-17.

Hübner, M. M. C., Matos, M. A, \& Serra, C. (2002). Redes de relações condicionais e leitura recombinativa: pesquisando o ensinar a ler. Arquivos Brasileiros de Psicologia, 52, 284-303.

Hübner-D’Oliveira, M. M., \& Matos, M. A. (1993). Controle discriminativo na aquisição da leitura: efeito da repetição e variação na posição das sílabas e letras. Temas em Psicologia, 2, 99-108.

Instituto Nacional de Estudos e Pesquisas Educacionais Anísio Teixeira. (2001). Sistema nacional de avaliação da educação básica - SAEB 2001. Recuperado de http://www.inep.gov.br

Jefrey, W. E., \& Samuels, J. (1967). Effect of method of reading training on initial learning and transfer. Journal of Verbal Learning and Verbal Behavior, 6, 354-358.

Mackay, H. A., \& Sidman, M. (1984). Teaching the new behavior via equivalence relations. In P. H. Brooks, R. Sperber \& C. McCauley (Eds.), Learning and cognition in mentally retarded. Hillsdale, NJ: Lawrence Erlbaum.

Matos, M. A., Avanzi, A. L., \& Mcllvane, W. J. (2006). Rudimentary reading repertoires via stimulus equivalence and recombination of minimal units. The Analysis of Verbal Behavior, 22, 3-19.

Matos, M. A., Hübner, M. M. C., \& Peres, W. (1997). Oralização e cópia: efeitos sobre a aquisição de leitura generalizada recombinativa. Temas em Psicologia, 1, 47-65.

Matos, M. A., Hübner, M. M. C., \& Peres, W. (1999). Leitura generalizada: procedimentos e resultados. In R. A. Banaco (Org.), Sobre comportamento e cognição: aspectos teóricos, metodológicos e de formação em análise do comportamento e terapia cognitivista (Vol. 1, pp. 470-488). Santo André, SP: ARBytes.

Maués, A. S. (2007). A recombinação de letras no ensino e emergência da leitura recombinativa em crianças da pré-escola. Dissertação de Mestrado, Programa de Pós-Graduação em Psicologia, Universidade Federal do Pará, Belem, PA.

Melchiori, L. E., de Souza, D. G., \& de Rose, J. C. (2000). Reading, equivalence, and recombination of units: $A$ replication with students with different learning stories. Journal of Applied Behavior Analysis, 33, 97-100. 
Mueller, M. M., Olmi, D. J., \& Saunders, K. J. (2000). Recombinative generalization of within-syllabe units in prereading children. Journal of Applied Behavior Analysis, 33, 515-531.

Quinteiro, R. S. (2003). Aprendizagem de leitura receptiva e de comportamento textual: Efeito do número de palavras treinadas sobre o repertório recombinativo. Dissertação de Mestrado. Universidade de Brasília. Brasília, DF.

Rocha, A. M., \& Hanna, E. S. (1996a). Desenvolvimento de controle por unidades mínimas I: avaliação em testes de pareamento com o modelo. Resumos de Comunicações Científicas da XXVI Reunião da Sociedade Brasileira de Psicologia (p. 62). Ribeirão Preto, SP

Rocha, A. M., \& Hanna, E. S. (1996b). Desenvolvimento de controle por unidades mínimas II: Avaliação em testes de leitura oral. Resumos de Comunicações Científicas da XXVI Reunião da Sociedade Brasileira de Psicologia (pp. 62-63). Ribeirão Preto, SP.

Serejo, P., Hanna, E. S., de Souza, D. G., \& de Rose, J. C. (2007). Leitura e repertório recombinativo: Efeito da quantidade de treino e da composição dos estímulos. Revista Brasileira de Análise do Comportamento, 3, 191-212.

Sidman, M. (1971). Reading and auditory-visual equivalences. Journal of Speech and Hearing Research, 14, 5-13.

Sidman, M. (1994). Equivalence relations: A research story. Boston, MA: Authors Cooperative.

Sidman, M., \& Cresson, O. (1973). Reading and cross-modal transfer of stimulus equivalence in severe retardation. American Journal of Mental Deficiency, 77, 515523.

Sidman, M., \& Tailby, W. (1982). Conditional discrimination vs. matching to sample: An expansion of the testing paradigm. Journal of the Experimental Analysis of Behavior, 37, 5-22.

Silberman, H. F. (1964). Exploratory research on a beginning reading program_(Relatório \# TM-895/100/00). Santa Monica: System Developmental Corporation.

Skinner, B. F. (1957). Verbal behavior. New York: Appleton.

Snow, C. E., Griffin, P., \& Burns, M. S. (2005). Knowledge to support the teaching of reading: Preparing teachers for a changing world. San Francisco: Jossey-Bass. 
Stromer, R., \& Mackay, H. A. (1992). Spelling and emergent picture-printed word relations established with delayed identity matching to complex samples. Journal of Applied Behavior Analysis, 25, 893-904.

Stromer, R., Mackay, H. A., \& Stoddard, L. T. (1992). Classroom applications of stimulus equivalence technology. Journal of Behavioral Education, 2, 225-256.

Wetherby, B. C. (1978). A functional analysis of miniature linguistic system learning in preschool children. Dissertation Abstracts International, 38, 6207-6208.

Wetherby, B. C., \& Striefel, S. (1978). Application of miniature linguistic system or matrix training procedures. In R. Schiefellbusch (Ed.), Bases of language intervention (pp. 317-356). Baltimore: University Park Press.

Elenice S. Hanna, Professora Associada do Departamento de Processos Psicológicos Básicos, Instituto de Psicologia, Universidade de Brasília, Docente do Programa de Pós-Graduação em Ciências do Comportamento da UnB, Pesquisadora do Instituto Nacional de Ciência e Tecnologia sobre Comportamento, Cognição e Ensino (INCT-ECCE - MCT/CNPq/FAPESP). Instituto de Psicologia, Universidade de Brasília, CEP: 70.910-900, Brasília-DF.Endereço eletrônico: hanna@unb.br

Camila Akemi Karino, Coordenadora-geral de Instrumentos e Medidas do Instituto Nacional de Estudos e Pesquisas Educacionais Anísio Teixeira (INEP). Estudante de pós-graduação em Psicologia Social, do Trabalho e das Organizações da Universidade de Brasília (UnB).Endereço eletrônico: camilaakarino@gmail.com

Victor Tadeu, Psicólogo e Bacharel pela Universidade de Brasília, Especialista em Assistência Social da Secretaria de Desenvolvimento Social e Transferência de Renda (SEDEST) do Governo do Distrito Federal. HIGS 706, Bloco “D”, Casa 60 - Plano Piloto. CEP: 70350-754, Brasília-DF. Endereço eletrônico: victor.tadeu@gmail.com

Deisy G. de Souza, Professora Titular do Departamento de Psicologia da Universidade Federal de São Carlos, Docente dos Programas de Pós-Graduação em Psicologia e em Educação Especial da UFSCar, Pesquisadora do Instituto Nacional de Ciência e Tecnologia sobre Comportamento, Cognição e Ensino (INCT-ECCE - MCT/CNPq/ FAPESP).Endereço eletrônico:ddgs@power.ufscar.br

Recebido em:22/03/2010

Aceito em: 10/05/2010 
